\title{
Image-guided percutaneous ablation for the treatment of lung malignancies: current state of the art
}

\author{
Alfredo Páez-Carpio ${ }^{\text {* }}$ D , Fernando M. Gómez ${ }^{1,2}$, Gemma Isus Olivé ${ }^{1}$, Pilar Paredes ${ }^{3}$, Tarik Baetens², \\ Enrique Carrero ${ }^{4}$, Marcelo Sánchez ${ }^{1}$ and Ivan Vollmer ${ }^{1}$
}

\begin{abstract}
Image-guided percutaneous lung ablation has proven to be a valid treatment alternative in patients with early-stage non-small cell lung carcinoma or oligometastatic lung disease. Available ablative modalities include radiofrequency ablation, microwave ablation, and cryoablation. Currently, there are no sufficiently representative studies to determine significant differences between the results of these techniques. However, a common feature among them is their excellent tolerance with very few complications. For optimal treatment, radiologists must carefully select the patients to be treated, perform a refined ablative technique, and have a detailed knowledge of the radiological features following lung ablation. Although no randomized studies comparing image-guided percutaneous lung ablation with surgery or stereotactic radiation therapy are available, the current literature demonstrates equivalent survival rates. This review will discuss image-guided percutaneous lung ablation features, including available modalities, approved indications, possible complications, published results, and future applications.
\end{abstract}

Keywords: Non-small cell lung carcinoma, Metastatic lung disease, Percutaneous thermal ablation

\section{Key points}

- Image-guided percutaneous lung ablation is a technique equivalent to surgery and stereotactic radiation therapy to treat patients with early-stage non-small cell lung cancer or oligometastatic lung disease.

- Modalities available include radiofrequency ablation, microwave ablation, and cryoablation.

- Careful selection of patients amenable to ablative treatment is essential, with the tumor's size being the most critical variable.

- $\quad \mathrm{CT}$ and PET/CT play an essential role in the immediate and long-term follow-up of patients treated with percutaneous ablation.

\footnotetext{
*Correspondence: paez@clinic.cat

1 Department of Radiology, CDI, Hospital Clínic, University of Barcelona,

Barcelona, Spain

Full list of author information is available at the end of the article
}

\section{Background}

Lung cancer has long been the leading cause of cancer incidence, with around 2.1 million new cases each year and cancer-related mortality worldwide, representing close to 1 in 5 (18.4\%) cancer-related deaths [1]. Similarly, the lung is the second most common site for metastases from other malignant tumors [2]. Furthermore, the widespread use of chest computed tomography (CT) has dramatically increased the early detection of potentially treatable lung tumors [3]. Many advances have been made in the diagnosis and treatment of malignant lung tumors. Although surgical resection remains the gold-standard treatment of early-stage non-small cell lung cancer (NSCLC), the increasing number of patients with comorbidities or other reasons for inoperability has led to an increase in the use of less invasive therapeutic options [3-6]. Moreover, several studies have demonstrated the efficacy of metastasectomy for the treatment of oligometastatic lung disease (OLD) $[7,8]$. Thus, as in 
the NSLCL, minimally invasive techniques have emerged as an option for inoperable patients [9].

In this regard, image-guided percutaneous lung ablation has significantly improved in recent years. Several advances regarding ablative modalities, procedure performance, patient selection improvements, and a greater understanding of the imaging findings observed after the procedure have been accomplished, especially in patients with NSCLC or OLD $[9,10]$. Currently, radiofrequency ablation (RFA), microwave ablation (MWA), and cryoablation (CA) are the only percutaneous ablative modalities with proven efficacy and safety in the treatment of lung malignancies [11]. They all have shown reasonable local disease control with acceptable complication rates while preserving lung function [12-14].

This review will discuss the different ablative modalities available, current indications, and the preprocedural management of image-guided percutaneous lung ablation. It will also address the most relevant aspects of treatment follow-up, imaging findings after the procedure, and the results obtained in the most relevant research studies published to date.

\section{Ablative modalities available for lung ablation}

Currently available modalities for image-guided lung ablation include RFA, MWA, and CA. All three are thermal ablation modalities that destroy tumor cells by directly applying extreme temperatures into the tumor and the safety margin. Although some publications mention the possible use of laser-induced thermotherapy (LITT) and irreversible electroporation (IRE), none of them reach the results achieved by the RFA, MWA, and CA $[15,16]$.

RFA is an electric current-based technique that heats tissue by agitating the electrons at a frequency of around $400 \mathrm{kHz}$. The ablative effect is produced by actively heating the ablation device, diffusing the temperature progressively and passively into the target lesion, thus elevating tissue temperature up to $60-100^{\circ} \mathrm{C}$ [17]. An expandable array with an electrode diameter of at least $10 \mathrm{~mm}$ larger than the target tumor has shown to ablate tumors successfully, ensuring a recurrence rate of $<10 \%$ in tumors with a maximum diameter of $<10 \mathrm{~mm}$ [18]. The lung is a very susceptible organ to be treated by means of RFA since the air in the lung parenchyma acts as an insulator and an area of low electrical conductivity, allowing the ablation of a larger volume of tissue for a given energy than any other tissue [11]. As for its limitations, RFA is generally not recommended for the treatment of central tumors near large vessels and hilar structures. Although RFA is classically related to cardiac pacemakers' interference, this is no longer the case when using modern equipment [19].
MWA creates an electromagnetic field around the ablation device that varies between 915 and $2450 \mathrm{MHz}$, causing water molecules to rotate and, ultimately, heat by friction over the target lesion [20]. MWA produces a more uniform ablation zone, and temperature peaks occur much faster than RFA [21, 22]. However, the theoretical superiority of MWA has not resulted in results significantly different from those already reported for RFA: tumor diameter $(>3 \mathrm{~cm})$ and proximity to a large vessel remain the main factors associated with a higher incidence of incomplete treatment [23]. Nevertheless, MWA may allow the treatment of larger tumors than RFA since tissue impedance does not limit the action of MWA [24, 25].

CA generates sub-zero temperatures forming an ice ball to cover the tumor and safety margin at $-40^{\circ} \mathrm{C}$. During CA, liquefied gas such as nitrogen or argon passed through cryoprobes to create temperatures as low as $-190^{\circ} \mathrm{C}$. Cytotoxic cell destruction is achieved at temperatures below $-20^{\circ} \mathrm{C}$ [26]. After the freezing phase, a thawing phase follows by replacing the liquefied gas with helium or internally heating the needle. The whole freezing-thawing process is repeated until obtaining an effective ablation [9, 27]. Structures containing a collagenous matrix, such as blood vessels and bronchial tubes, remain intact after CA. This feature makes it ideal for treating tumors near the pulmonary hilum or major vessels [28]. One limitation of $\mathrm{CA}$ is that available protocols describe the need for up to three freeze-thaw cycles to achieve a correct ablative treatment, making the procedure longer than RFA and MWA. Another limitation is a greater complexity when handling the equipment since it requires experience operating argon gas. Also, satisfactory ablative treatment often requires the placement of two to four probes within the target lesion, which increases the difficulty of the procedure [29]. However, one advantage of using multiple probes is customizing the treated area's morphology during the procedure.

Current scientific evidence indicates similar therapeutic results for all three ablative modalities. Therefore, it is necessary to carefully consider the tumor features and the patient's characteristics when choosing the ablative technique. For example, although RFA is a widely available technique with proven efficacy and safety, MWA may be preferable in larger tumors. Lung MWA can produce ablative areas of about $6 \mathrm{~cm}$, compared to $3 \mathrm{~cm}$ for RFA. Although MWA may be more effective on tumors near the pulmonary hilum and major vessels since the heat dissipation effect does not affect its therapeutic effect, the ablation volume is difficult to control, which increases the risk of bronchial fistula if used near the pulmonary hilum. 
Among the advantages of cryoablation compared to heat-based techniques, there is evaluating the ablation site during the procedure. This feature allows the optimization of the treatment in real-time. Cryoablation is an effective alternative in tumors near the great vessels, airways, pericardium, and subpleural lesions, as it tends to cause less pain to the patient than RFA and MWA. As for its disadvantages, CA is not recommended in patients with coagulopathies since a higher rate and severity of lung bleeding. Higher hemoptysis rates have also been reported compared to heat-based modalities [30] (Table 1).

\section{Planning and procedure Patient selection}

The decision to treat lung malignancies by means of image-guided percutaneous ablation has to be made preferably in a tertiary center by a multidisciplinary team including thoracic surgeons, pneumologists, medical oncologists, radiation oncologists, anesthesiologists, and radiologists with expertise in lung ablation [31].
Currently, the indication for percutaneous ablative treatment includes patients with NSCLC or oligometastatic lung disease.

Current indications for image-guided percutaneous lung ablation in NSCLC are: (1) patients with stage Ia NSCLC with contraindications for surgery or stereotactic radiation therapy (SRT) [32, 33]; (2) medically inoperable stage Ia NSCLC; (3) unresectable local recurrence of NSCLC; (4) patients with multiple and synchronous NSCLC (proven by biopsy or by a history of lung cancer), suitable for definitive ablative treatment; and (5) in association with tyrosine kinase inhibitors (TKI), aiming to control the residual tumor volume $[34,35](6)$ Recurrence after surgery or radiation therapy (Table 2).

Indications for image-guided percutaneous lung ablation in OLD are less established. Although no prospective studies compare the available alternatives, current guidelines established by the consensus of multidisciplinary committees place complete surgical resection as the treatment of choice in these patients [6]. However, in patients considered at high surgical risk,

Table 1 Comparison between ablative techniques in lung ablation

\begin{tabular}{|c|c|c|c|}
\hline & RFA & MWA & CA \\
\hline Mechanism & Electric current & Electromagnetic field & Argon gas \\
\hline Temperature & $60-100^{\circ} \mathrm{C}$ & $60-150^{\circ} \mathrm{C}$ & Sub-zero \\
\hline Ablation zone size & $3 \mathrm{~cm}$ & $6 \mathrm{~cm}$ & Less than heat-based modalities \\
\hline Applicators & Single probe: straight or expandable & $\begin{array}{l}\text { Single or multiple probes, straight or } \\
\text { with one to three loops }\end{array}$ & Single or multiple probes (2-3) \\
\hline Advantages & $\begin{array}{l}\text { Widely available and proven } \\
\text { Lung is highly susceptible }\end{array}$ & $\begin{array}{l}\text { Uniform ablation zone } \\
\text { Larger ablated area } \\
\text { No heat-sink effect }\end{array}$ & $\begin{array}{l}\text { Suitable for lesions near large vessels or perihilar } \\
\text { Less painful }\end{array}$ \\
\hline Disadvantages & $\begin{array}{l}\text { Not recommended near large vessels } \\
\text { or pulmonary hilum } \\
\text { Interferes with the heart's conduc- } \\
\text { tion system }\end{array}$ & $\begin{array}{l}\text { Superiority to RFA has not been proven } \\
\text { It may cause a higher complication rate }\end{array}$ & $\begin{array}{l}\text { Increased difficulty } \\
\text { May cause more lung bleeding }\end{array}$ \\
\hline Ideal patient & $\begin{array}{l}\text { Peripheral tumor, }<3 \mathrm{~cm} \\
\text { No pacemaker }\end{array}$ & $\begin{array}{l}\text { Peripheral or central tumors } \\
\text { Lesion can be }>3 \mathrm{~cm} \\
\text { It can be used with pacemakers }\end{array}$ & $\begin{array}{l}\text { Peripheral or central lesion can be }>3 \mathrm{~cm} \\
\text { No bleeding risk factors }\end{array}$ \\
\hline
\end{tabular}

RFA radiofrequency, MWA microwave, $C A$ cryoablation, $C T$ computed tomography

Table 2 Indications for image-guided percutaneous lung ablation

Level of evidence

Main indications

1. Inoperable stage IA NSCLC

2

2. Oligometastatic colorectal cancer with up to 3 lung nodules $(\leq 2 \mathrm{~cm})$ and contraindication to surgery

2

Alternative indications

1. Multiple and synchronous NSCLC suitable for definitive ablative treatment

3

2. Inoperable NSCLS in other stages

3. Oligometastatic lung disease from other tumors and contraindication to surgery

NSCLC non-small cell lung cancer 
percutaneous lung ablation is a feasible option, offering local efficacy similar to surgery in carefully selected patients. Percutaneous ablation is performed mainly in metastasis from colorectal, lung and renal cancer, melanoma, hepatocellular carcinoma, and sarcoma. Patients amenable to ablative therapy should have a maximum of four lesions per lung, all with a maximum tumor diameter of $<3.5 \mathrm{~cm}$ [36-39]. Also, percutaneous lung ablation may be proposed as rescue therapy for local recurrence in previously irradiated lung metastasis [40] (Table 2).

Absolute contraindications to image-guided percutaneous ablation include severe lung emphysema with bullae (due to the risk of untreatable fistula and respiratory failure), life expectancy of $<3$ months, patients with Eastern Cooperative Oncology Group (ECOG) $>2$, non-correctable hemorrhagic diathesis, and the presence of small cell lung carcinoma [41]. Relative contraindications are tumors located near large vessels or pulmonary hilum $(<1 \mathrm{~cm})$ lung function deterioration [42] (Table 3).

Table 3 Contraindications for image-guided percutaneous lung ablation

Absolute

Severe pulmonary emphysema with bullae

Life expectancy of $<3$ months

ECOG scale $>2$

Small cell lung carcinoma

Non-correctable hemorrhagic diathesis

Relative

Impaired lung function

Tumors located near large vessels or hilum (RFA)

Cardiac pacemakers (RFA)

Correctable hemorrhagic diathesis

ECOG Eastern Cooperative Oncology Group, RFA radiofrequency ablation

\section{Preprocedural evaluation}

Preprocedural evaluation for lung ablation is similar to any surgical or minimally-invasive procedure, with assessment and management of cardiopulmonary and systemic conditions, as well as control of bleeding risk factors. A joint effort between radiology teams and an anesthesiology team specially dedicated to interventional radiology procedures is necessary for a correct evaluation. Therefore, it is highly desirable to schedule a visit with the patient, the nursing team, and both specialists on the day of the procedure to evaluate the risks and explain the procedure. A fluid and effective communication between the team and the patient is essential during this visit. Also, a recent cross-sectional imaging study is imperative before the procedure (maximum 4 weeks old). It will allow the radiologist to assess the tumor's size and location, the proximity of the lesion to critical structures, and lymph node involvement [31, 43].

According to the Society of Interventional Radiology and the Cardiovascular and Interventional Radiology Society of Europe guidelines, percutaneous lung ablation is considered a high-risk bleeding procedure. Hence the necessity to control INR and platelet count values correctly [42, 44]. Moreover, any anticoagulant and antiplatelet used by the patient must be adequately evaluated and adjusted before the procedure [45] (Table 4).

Regarding antibiotic prophylaxis, although some authors recommend the use of a single dose of antibiotic prophylaxis before a lung ablation, there is no consensus on this implementation. Some risk factors, such as the presence of a single lung, previously irradiated lung parenchyma, primary tumors, or previously compromised parenchyma, may lead to the use of antibiotic prophylaxis. Protocols include amoxicillin-clavulanate or ofloxacin continued for 3-7 days after ablation [46].

Table 4 Management of bleeding risk factors before image-guided percutaneous lung ablation

\author{
Pre-procedure laboratory testing and management \\ INR: routinely recommended. Correct to $<1.5$ \\ aPTT: routinely recommended in patients receiving UFH. Stop or reverse UFH for values $>1.5 \times$ control \\ Platelet count: routinely recommended. $<50,000$ : transfuse \\ Hematocrit: routinely recommended. No recommended threshold for transfusion
}

Anticoagulant and antiplatelet management

Clopidogrel: withhold for five days before procedure. Resume the day after procedure

Aspirin: withhold for 3-5 days before procedure. Resume the day after procedure

LMWH: withhold for $24 \mathrm{~h}$ or up to two doses. Resume the $12 \mathrm{~h}$ after procedure

Warfarin: Withhold five days until target INR $<1.5$; consider bridging for high thrombosis risk cases. Resume the day after procedure

INR international normalized ratio, aPTT activated partial thromboplastin time, UFH unfractionated heparin, LMWH low-molecular-weight heparin 


\section{Anesthesia management}

In addition to local anesthesia through the probe path, both conscious sedation, recently named procedural sedation and analgesia (PSA) [47], or general anesthesia are valid options in image-guided percutaneous lung ablation [48]. Therefore, it is essential that an anesthesiologist, preferably one with experience in interventional radiology procedures, be always present during the procedure. The anesthesiologist must be in charge of monitoring the patient, diagnosing and treating possible early complications, and ensuring the patient's analgesia, comfort and immobility.

The indication of which type of anesthesia to use depends on the tumor's location, the procedure's technical difficulty, the patient's cardiopulmonary and systemic conditions. Experience of anesthesiology and radiology teams with the chosen anesthetic technique should also be considered. Although general anesthesia guarantees the patient's immobility during the procedure, resulting in less periprocedural pain and lower procedure interruption rates than PSA, the use of general anesthesia may result in a significant increase of anestheticinduced immunosuppression [49]. General anesthesia also increases the procedure's total cost and duration and pneumothorax risk when positive pressure is used $[50,51]$. PSA's main risks are respiratory depression and patients' movement during the radiological intervention [47]. Nevertheless, comparative studies between general anesthesia and PSA have not resulted in differences in technical success, feasibility, or complications [31, 52].

\section{CT protocol}

For evident reasons (lung air prevents other imaging techniques), CT is the only available imaging modality to place the ablation probe through the lung into the lesion. CT has three different modalities in this regard: conventional computed tomography-guided technique (CCT), CT-fluoroscopy-guided technique (CTF), and cone-beam CT-guided technique (CBCT). Regardless of modality, any CT-guided procedure has a standard workflow: a preprocedural, an intraprocedural and a postprocedural phase.

Before the procedure, clinical history should be carefully evaluated, in particular previous imaging tests. After acquiring a preprocedural baseline imaging test, the percutaneous access must be marked using a radiopaque grid locator in CCT or CTF or a specific guidance software in the case of CBCT (Fig. 1). Before starting the procedure, the $\mathrm{CT}$ acquisition parameters should be adjusted to allow minimum irradiation for the interventional team and the patient while maintaining sufficient quality to perform the procedure without difficulties (Table 5) [53-55].
For CTF or CCT, the patient is placed in prone, lateral, or supine decubitus on the CT table, depending on the lesion's location and the optimal access. CCT performs intermittent spiral CT scans that are usually limited to the biopsy. While intermittent spiral CT is being performed, the operator leaves the CT room and is not exposed to radiation [56]. This technique, while preventing radiation exposure to the radiologist, is timeconsuming. Also, small subpleural lesions $(<1 \mathrm{~cm})$ are challenging to approach, given their movement with respiration and the impossibility of correcting the probe trajectory in real-time.

Compared to CCT, the procedure time is shorter using CTF. The radiologist directly handles the probe and does not leave the CT room. By manipulating the needle in real-time, subpleural and small lesions are easily approached using this technique. Although CTF may be associated with increased radiation exposure to the operator, if standard radiological prevention measures are used, CTF radiation exposure to the operator does not significantly differ from CCT $[57,58]$.

In recent years $\mathrm{CBCT}$ has gained significance as an alternative to $\mathrm{CCT}$ and $\mathrm{CBF}$ in image-guided lung procedures. The CBCT system offers advanced needle planning under real-time needle guidance, using a combination of 3D images and fluoroscopy, allowing visualization of the needle's expected trajectory from the skin to the target lesion. Also, the increased workspace provided by the $\mathrm{C}$-arm cone-beam system facilitates needle placement and may speed up the procedure compared to CBF and CCT [59]. Furthermore, CBCT has been shown to have a similar radiological exposure risk to $\mathrm{CBF}$ and may be a faster technique than CTF $[60,61]$.

Regarding the patient's radiation dose, there are several strategies to reduce it to a minimum without compromising the image-guided procedure's quality. Multiple factors contribute to the radiation dose during a CT-guided interventional procedure (Table 5) [55]. One thing to keep in mind is that the preprocedural scan does not have to have the same radiological quality as a diagnostic scan. We can modify the CT parameters to acquire the image with the minimum possible radiation while still being sufficient to perform the procedure. In this regard, several studies have published results of decreased radiation doses to the patient and the operator by modifying $\mathrm{CT}$ parameters such as $\mathrm{kV}$, mAs, longitudinal scan length, and slice thickness in CT-guided lung biopsies [53, 62, 63]. Another strategy that has been shown to dramatically decrease patient radiation dose levels during CTF without significantly compromising the results and duration of the procedure is the use of intermittent multislice fluoroscopy rather than continuous single-slice fluoroscopy [56]. 


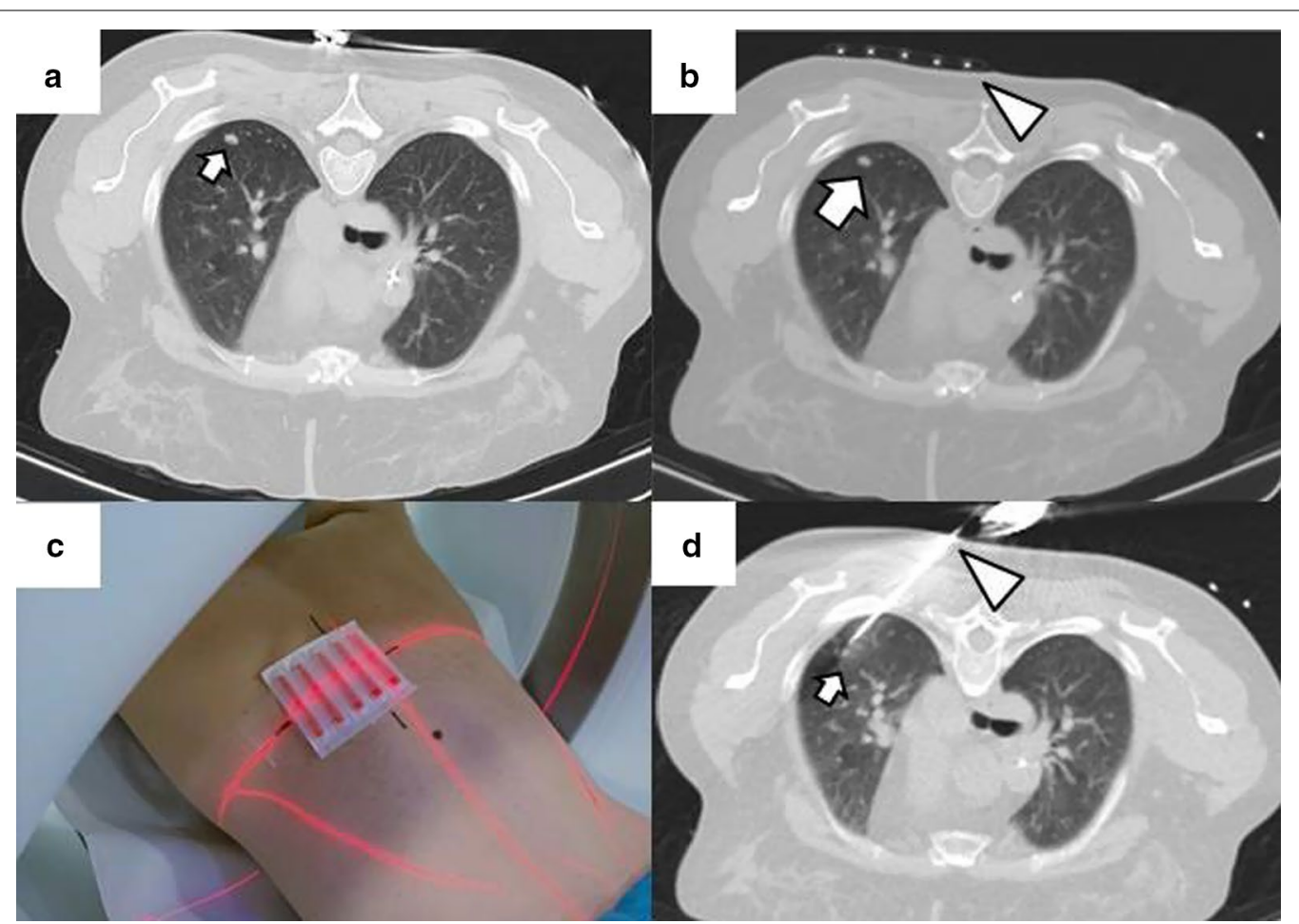

Fig. 1 Percutaneous access marking for CTF-guided lung ablation. a Preprocedural CT of a patient scheduled for treatment by image-guided percutaneous lung ablation of a single lung colon cancer metastasis located in the left upper lobe (arrow). Note that the CT scan was performed in the position chosen to perform the procedure (prone). $\mathbf{b}$ Marking of the lesion with a radiopaque grid (triangle). The scanner parameters were modified to decrease the exposure to ionizing radiation of the operator and the patient. Hence the decreased image quality. c Example of the marking procedure. The vertical axis is marked with the radio-opaque marker, while the horizontal axis is provided by the CT laser marking (acknowledgment to our resident, Dr. Tomás Fernández, for volunteering for the figure). $\mathbf{d}$ CTF-guided percutaneous access to the lesion. Note that the access coincides with the point marked in (b) (triangle)

Table 5 Scan parameters recommended for CT-guided lung ablation

\begin{tabular}{ll}
\hline kV (range) & $80-120 \mathrm{kV}$ \\
mAs (range) & $20-50 \mathrm{mAs}$ \\
Rotation time & $0.5 \mathrm{~s}$ \\
Collimation & $1 \times 10 \mathrm{~mm}$ \\
CTDI $_{\text {vol }}$ unit & CTF: mGy/s \\
& CCT: mGy \\
& CBCT: mGy and mGy/s \\
Tube current modulation & Not necessary \\
Image reconstruction & Eight frames per second \\
Longitudinal scan length & Smallest possible \\
Slice thickness & 4 mm \\
Typical accumulated CTDI & $75-100$ mGy \\
Typical accumulated DLP & $1000-1200$ mGy $\times$ cm \\
\hline
\end{tabular}

$\mathrm{CT}$, computed tomography; $\mathrm{CTF}$; $\mathrm{CCT}$; CBCT; $\mathrm{kV}$, kilovolt; $\mathrm{mAs}$, milliamps; $\mathrm{CTDI}_{\mathrm{vol}}$ volume $\mathrm{CT}$ dose index; DLP; dose-length product

Finally, it is advisable to perform a postprocedural acquisition to evaluate the ablation result and rule out immediate complications. The CT parameters should be adequate to make a correct radiological diagnosis without considerably increasing the patient radiation dose [55]".

In addition to conventional radiation protection measures, CTF has different modalities to minimize radiation exposure. Depending on the scanner manufacturer, different softwares are available to reduce radiation exposure. For example, a software widely used in daily clinical practice allows dose reduction and low-dose protocols, such as turning off X-ray emission where it is not needed and reducing the dose to sensitive organs. Another application allows a significant reduction of radiation exposure to the radiologist's hands while performing the procedure. Furthermore, another specific software allows the intervention to be performed with 1 or 3 combined and simultaneous slices, allowing better navigation and reducing the procedure duration and radiation exposure. Finally, other software allows 3D navigation in CT-guided procedures through multiplanar reconstructions via $2 \mathrm{D}$ acquisitions [64]. 


\section{Procedure}

Depending on the number of probes, the needle should pass through the tumor (single probe) or its edges (multiple probes). However, when expandable probes are used on small tumors, perforating the tumor is not required, as long as one of the deployed arrays includes the tumor (Fig. 2). The electrode must also be at least $10 \mathrm{~mm}$ larger than the tumor's maximum diameter [18].

While placing the probe in the target lesion, the tumor's location and its situation concerning the pleural fissures and bronchovascular structures should be considered. Subpleural lung tumors may be challenging to treat by direct puncture perpendicular to the pleura, as the probe may not be optimally anchored in the lung, thus, moving while breathing. Therefore, it is best to direct the probe tangentially to the pleura to properly anchor it in the lung parenchyma (Fig. 3). However, when using cryoablation during the first freezing cycle, it is possible to attach the probe to the lesion in order to place the second needle, a technique known as stickfreeze [65]. For central tumor ablation, the needle position should be parallel to the adjacent bronchovascular structures. Using CA this risk does not exist, which allows the tip to be directed towards the pulmonary hilum, as this is the area that offers maximum probe control. It is also important to anticipate a decrease in lung volume during ablation, which will cause the ablation probe to end up closer than expected to vital structures [48] (Fig. 4).

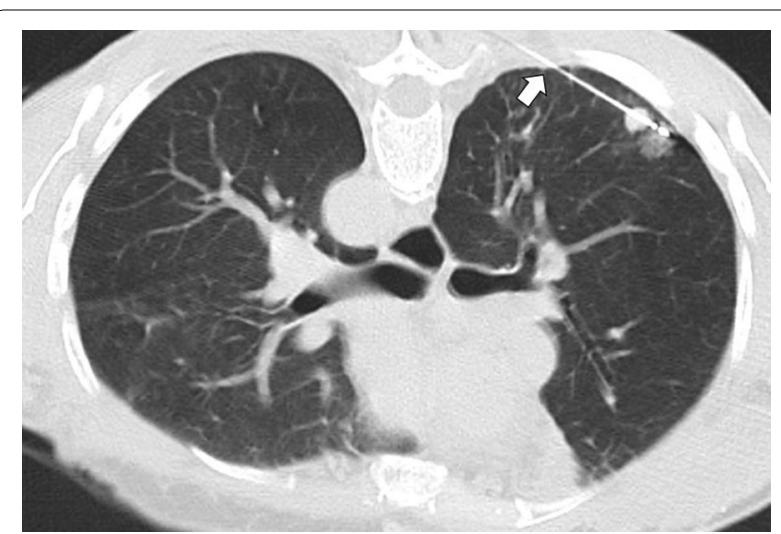

Fig. 3 Correct positioning of the ablation probe while treating a subpleural tumor. RFA of a subpleural nodular lesion in the lower right lobe, performed with a straight needle. Note that the needle makes a tangential route to the lesion (white arrow), evading the seemingly easier direct approach (triangle). This approach is necessary to allow a better anchorage in the lung parenchyma, thus avoiding the needle's non-voluntary displacement

In tumors located near sensitive structures (e.g., mediastinum, pleura, great vessels), it is possible to use adjunctive thermoprotection techniques during percutaneous lung ablation. Available techniques include manual traction using the ablation probe, iatrogenic pneumothorax, and hydrodissection. As previously stated, manual traction is possible using expandable electrodes or

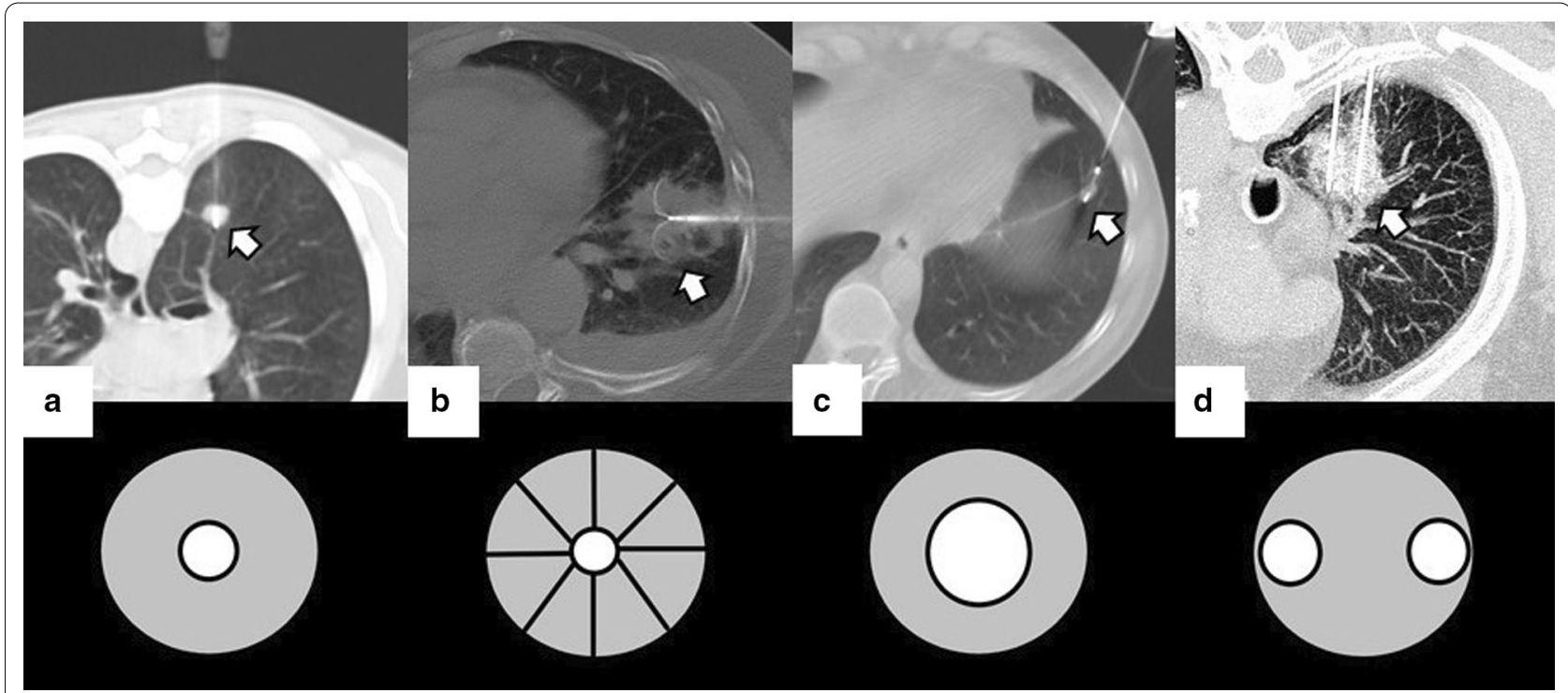

Fig. 2 Correct positioning of ablation probes in the target lesion, with schematic illustrations of each ablative alternative. a CT-guided percutaneous RFA treatment with a straight needle of a metastatic colon cancer lesion in the lower right lobe. Note the probe's correct positioning in the center of the tumor (arrow). b CT-guided percutaneous RFA treatment with an expandable needle of a colon cancer metastasis. The probe's electrodes include the entire lesion (triangles). c CT-guided percutaneous MWA treatment with a single straight needle of a renal cancer metastatic lesion in the lower left lobe. As in (a), the probe passes through the center of the tumor (arrow). $\mathbf{d}$ CT-guided percutaneous CA of a stage I NSCLC in the lower right lobe with two straight ablation probes. If two or more ablation probes are used, they should be placed at the tumor's edges 
cryoprobes, as both can archor the tumor during the procedure. The formation of an iatrogenic pneumothorax makes it possible to separate the tumor from the pleura and mediastinum during ablation. Finally, using hydrodissection, a variable amount of solution can be injected into the mediastinum using a small-caliber needle to avoid injuring it while performing the ablation [66].

In the event of treating lesions in both lungs, it is possible to treat them in a single session, provided that the patient meets specific inclusion criteria and that a radiological control is performed between each lung treatment. Given the risk of developing a bilateral pneumothorax. The passage of an electrode through a major pulmonary fissure should also be avoided. Also, the nodules should not be in contact with the pleura in both lungs [67].

A CT scan must be performed immediately after the procedure to rule out severe complications. Depending on the patient's condition, monitoring in a hospitalization room can vary between 24 and $48 \mathrm{~h}$. An additional CT scan is optional during this period. The radiologist must be personally involved in the clinical follow-up of the patient.

\section{Complications}

Regardless of the ablation mechanism, pneumothorax is the most frequent immediate complication following image-guided percutaneous lung ablation. Rates vary between 30 and $60 \%$, and most are asymptomatic, successfully managed mostly with clinical monitoring and sequential chest $\mathrm{x}$-rays (Fig. 5) [68, 69]. However, about $30 \%$ may have symptoms or an increase in size. Most improve promptly after the placement of a chest tube [10].

A rare complication is a late pneumothorax, defined as a pneumothorax occurring as early as $4 \mathrm{~h}$ after the procedure, almost always due to a bronchopulmonary fistula. This complication is also usually managed by placing a chest tube $[69,70]$. MWA may be associated with an increased risk of developing bronchopulmonary fistulas, possibly due to higher temperatures during the procedure and a larger ablation area [71].

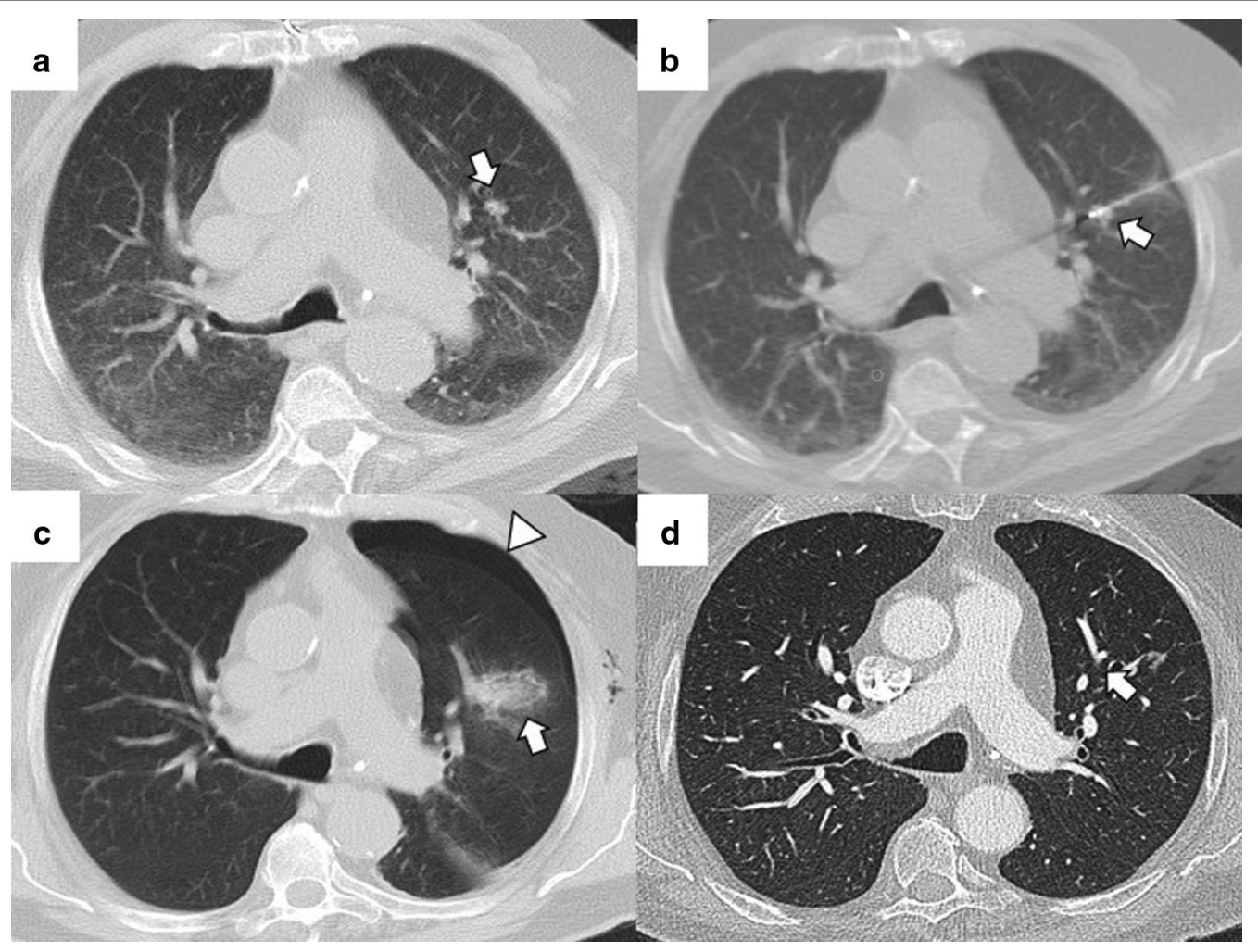

Fig. 4 Lung parenchyma retraction while performing an image-guided percutaneous lung ablation. $\mathbf{a}$, b RFA treatment with a straight needle of a metastatic lesion of a colon adenocarcinoma located in the left upper lobe, very close to the pulmonary hilum (white arrow). c After treatment, the treated area presents an image with a consolidative center and a ground-glass peripheral halo, suggesting a complete treatment (white arrow). A discrete retraction of the pulmonary parenchyma is evident, which, added to the presence of a mild pneumothorax (white triangle), mobilizes the hilar structures. $\mathbf{d}$ Control of the treated lesion after 12 months of RFA, no signs of recurrence are evident 
The incidence of small asymptomatic pleural effusions after ablative treatment is not uncommon and is most likely a reactive phenomenon [31]. The vast majority are asymptomatic and resolve spontaneously. However, even the slightest pleural effusion may warrant thoracentesis or even a chest tube placement in patients with low respiratory reserve. Thoracentesis or chest tube placement is required between 1 and 7\% of the patients treated [69].

The development of a hemothorax is a rare complication after percutaneous lung ablation, but it can be fatal if left untreated. We should suspect it in the event of a rapidly progressive pleural effusion, especially if there are signs of hypovolemia. It requires a radiological examination or thoracentesis to confirm the diagnosis (Fig. 6) [69]. Although most cases require only a chest tube, endovascular treatment may be necessary if active arterial bleeding is reported [31]. Parenchymal hemorrhage is another common complication after percutaneous lung ablation. The vast majority are self-limiting and are mostly related to the probe's path through the lung (Fig. 7). Some evidence indicates a higher rate of severe lung hemorrhage after CA [72].
Much rarer complications include the development of pneumonia or the presence of chronic obstructive disease exacerbation, both reported with the use of RFA [70]. Another sporadic complication is the injury of adjacent critical structures. Such structures include the nerve, mediastinum and diaphragm. A safe distance should always be taken between these structures and the probe, considering the lung parenchyma's possible retraction during the procedure [10]. Finally, an infrequent complication related only to CA is the development of shock secondary to an uncontrolled release of cytokines, also called cryoshock. This is usually related to the volume of ablation [72]. Finally, complications, depending on severity, may prolong hospital stay and costs.

\section{Postablation imaging follow-up}

Patients treated by percutaneous ablation must follow a strict and standardized scheme to detect and treat an incomplete ablative treatment since, unlike surgical resection, the treated zone remains in the lung parenchyma. CT is the modality of choice for radiological follow-up, although positron emission tomography

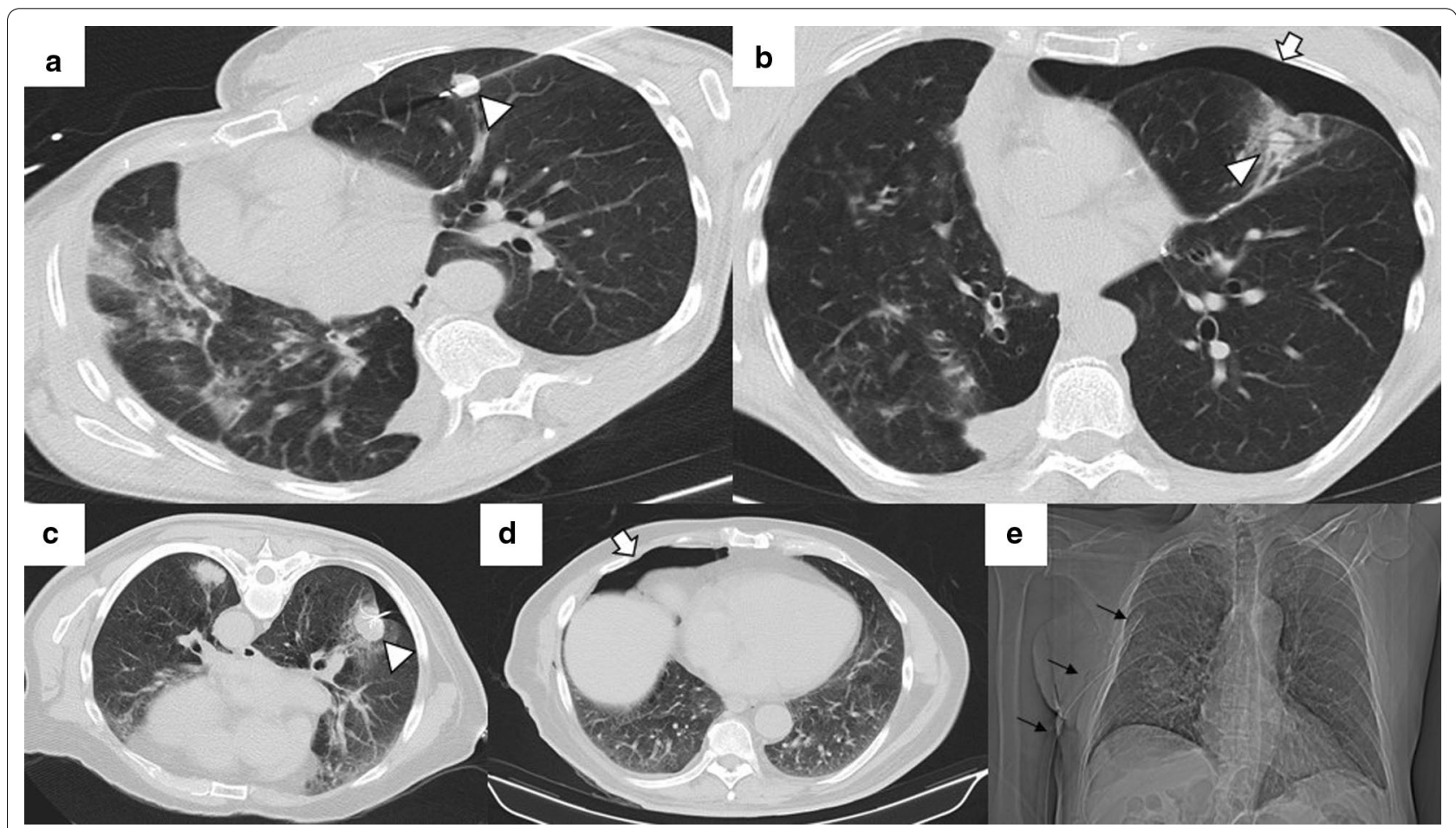

Fig. 5 Mild pneumothorax after image-guided percutaneous lung ablation. $\mathbf{a}, \mathbf{b}$ CT-guided MWA in a single lung metastasis from colon cancer in the upper left lobe. Note the correct probe position in the center of the lesion (triangle). In the CT performed immediately after the procedure, the patient presented a mild pneumothorax (arrow). The pneumothorax was resolved spontaneously without the need for a chest tube. Note the peripheral ground-glass halo with a central consolidation (triangle in $\mathbf{b}$ ), which indicates a correct treatment. $\mathbf{c}-\mathbf{e}$ CT-guided RFA lung ablation in a lung metastasis from a basal cell skin carcinoma. The expandable probe correctly englobes the lesion (triangle in c). In this patient, a pneumothorax was also observed immediately after the ablation. (arrow in $\mathbf{d}$ ). Although pneumothorax is similar to in A-B, the patient's clinical situation required a chest tube (black arrows in $\mathbf{e})$ 
(PET/CT) is becoming increasingly common. A recommended scheme for follow-up after treatment is as follows: the patient is monitored by a contrast-enhanced CT at $1,3,6,9,12,18,24$ months, and annually afterward [42]. Depending on availability, it is advisable to perform a PET/CT scan at 3 and 12 months after treatment and whenever there is a suspicion of recurrence on CT [73, 74] (Table 6).
We will discuss the morphological and metabolic changes visualized in the treated area during the radiological control, subdivided into four distinct phases: after-treatment-phase $(<24 \mathrm{~h})$, early-phase $(<24 \mathrm{~h}$ to 1 month), intermediate-phase (1 to 3 months), and latephase ( $>3$ months) (Table 7 ).

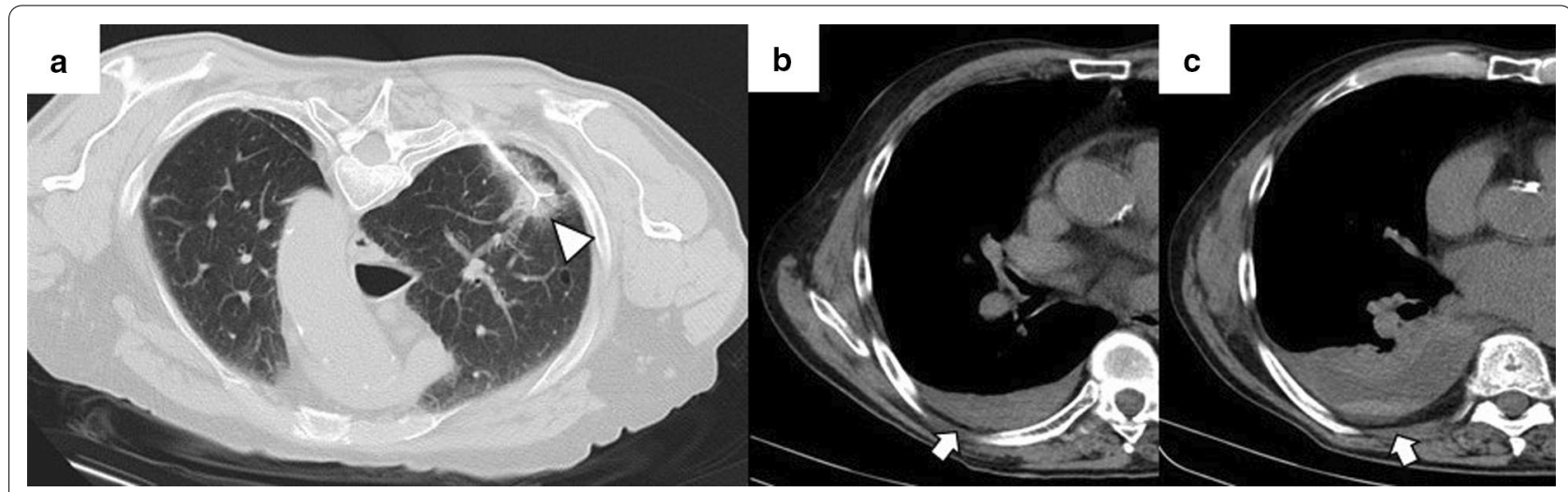

Fig. 6 Mild hemothorax after image-guided percutaneous lung ablation. a CT-guided percutaneous RFA of a stage 1 NSCLC located in the lower left lobe. Note the expanding tube encompassing the entire lesion. b CT scan immediately after the procedure where we observe a mild hyperdense pleural effusion, consistent with a mild hemothorax. c CT scan performed $24 \mathrm{~h}$ after the procedure shows a slight increase in the hyperdense pleural effusion and a discrete hyperdense level within the pleural effusion, confirming the hemothorax (arrow). However, after $48 \mathrm{~h}$ of clinical and radiological stability, the patient was discharged

Table 6 Follow-up Scheme after Image-Guided Percutaneous Lung Ablation

\begin{tabular}{lllllllll}
\hline Pretreatment & $\mathbf{1}$ month & $\mathbf{3}$ months & $\mathbf{6}$ months & $\mathbf{9}$ months & $\mathbf{1 2}$ months & $\mathbf{1 8}$ months & $\mathbf{2 4}$ months & Yearly \\
\hline CE-CT & CE-CT & CE-CT & CE-CT & CE-CT & CE-CT & CE-CT & CE-CT & CE-CT \\
PET/CT & & $P E T / C T$ & & & $P E T / C T$ & & & PET/CT* \\
\hline
\end{tabular}

CE-CT, contrast-enhanced computed tomography; $P E T / C T$, positron emission tomography/computed tomography

*In case of suspected tumor recurrence

Table 7 Radiological Follow-up after Image-Guided Percutaneous Lung Ablation

\begin{tabular}{|c|c|c|c|c|}
\hline & After-treatment-phase & Early-Phase & Intermediate-phase & Late-phase \\
\hline Successful treatment & $\begin{array}{l}\text { Consolidative center } \\
\text { surrounded by a } \\
\text { peripheral ground- } \\
\text { glass area }>5 \mathrm{~mm}\end{array}$ & $\begin{array}{l}\text { The peripheral ground- } \\
\text { glass opacity evolves } \\
\text { into a thin consolidative } \\
\text { area } \\
\text { The resulting consolida- } \\
\text { tion is typically more } \\
\text { extensive than the } \\
\text { original tumor }\end{array}$ & $\begin{array}{l}\text { Progressive decrease in the size of } \\
\text { the treated area } \\
\text { Persistence of a benign periabla- } \\
\text { tional enhancement, yet less than } \\
\text { the original tumor }\end{array}$ & $\begin{array}{l}\text { Three to six months after abla- } \\
\text { tion: stability in size. After six } \\
\text { months: progressive decrease } \\
\text { in size } \\
\text { Increased enhancement } \\
\text { compared to previous phases } \\
\text { may exist }\end{array}$ \\
\hline Unsuccessful treatment & $\begin{array}{l}\text { Irregular peripheral } \\
\text { nodular enhancement } \\
\text { within the consolida- } \\
\text { tive center }\end{array}$ & $\begin{array}{l}\text { Excessive growth of the } \\
\text { treated area } \\
\text { Irregular and peripheral } \\
\text { enhancement or within } \\
\text { central consolidation }\end{array}$ & $\begin{array}{l}\text { PET/TC: solitary focal or peripheral } \\
\text { FDG uptake or combined with a } \\
\text { focal uptake at the consolidative } \\
\text { center }\end{array}$ & $\begin{array}{l}\text { Enlargement of the treated area } \\
\text { after the first three months } \\
\text { that persists beyond six } \\
\text { months } \\
\text { Any FDG uptake suggests } \\
\text { recurrence }\end{array}$ \\
\hline
\end{tabular}




\section{After-treatment phase $(<24 \mathrm{~h})$}

The most common finding in RFA and MWA immediately after the procedure is a pattern consisting of a ground-glass peripheral halo surrounding a central consolidation. The presence of a ground-glass halo greater than $5 \mathrm{~mm}$ around the ablated zone suggests treatment success (Figs. 8 and 9) [75]. In contrast, the persistence of an irregular and enhancing nodular zone within the central consolidation is consistent with incomplete treatment. Other signs of incomplete ablation are the total or partial absence of the ground-glass peripheral area and the extension of such halo by less than $5 \mathrm{~mm}$ (Fig. 10) [76]. CA offers the advantage of differentiated the ablated area and the surrounding hemorrhage throughout the procedure, the former represented as a low attenuation zone ("ice ball") and the latter as a higher attenuation zone (Fig. 11). Towards the end of the procedure, the melted ice induces necrosis, hemorrhage, and edema, which manifest as a peripheral ground-glass halo surrounding a central consolidation, very similar to that observed in heat-based ablations (Fig. 12) [30].

\section{Early-phase (24 h to 1 month)}

In all ablative modalities, as the weeks progress, the ground-glass opacity surrounding the ablation site gradually resolves and is replaced by a thin residual consolidation zone that separates the central consolidation from the adjacent lung. The resulting consolidation is typically more extensive than the original tumor (Fig. 9c) [77]. At this stage, CT is the only technique available for radiological control. PET-CT has limited value due to the inability to differentiate fluorodeoxyglucose (FDG) uptake due to inflammation from that caused by a residual tumor (Fig. 13) [78]. Using CA, diffuse internal enhancement may occasionally occur, which resolves within a month [79].

\section{Intermediate-phase (1 to 3 months)}

Given the regression of edema, inflammation, and hemorrhage, the ablated area should have decreased in size compared to the size observed immediately after the procedure. The enhancement at this phase should be less than the original tumor, with a benign periablational enhancement persisting for up to 6 months [80]. In some cases, especially in large lesions, central cavitation secondary to the drainage of necrotic tissue by the adjacent bronchi can be seen throughout this phase [81]. Pleural thickening and a transient size increase in the hilar and mediastinal lymph nodes also occur during this phase [48]. FDG uptake peaks two weeks after ablation and

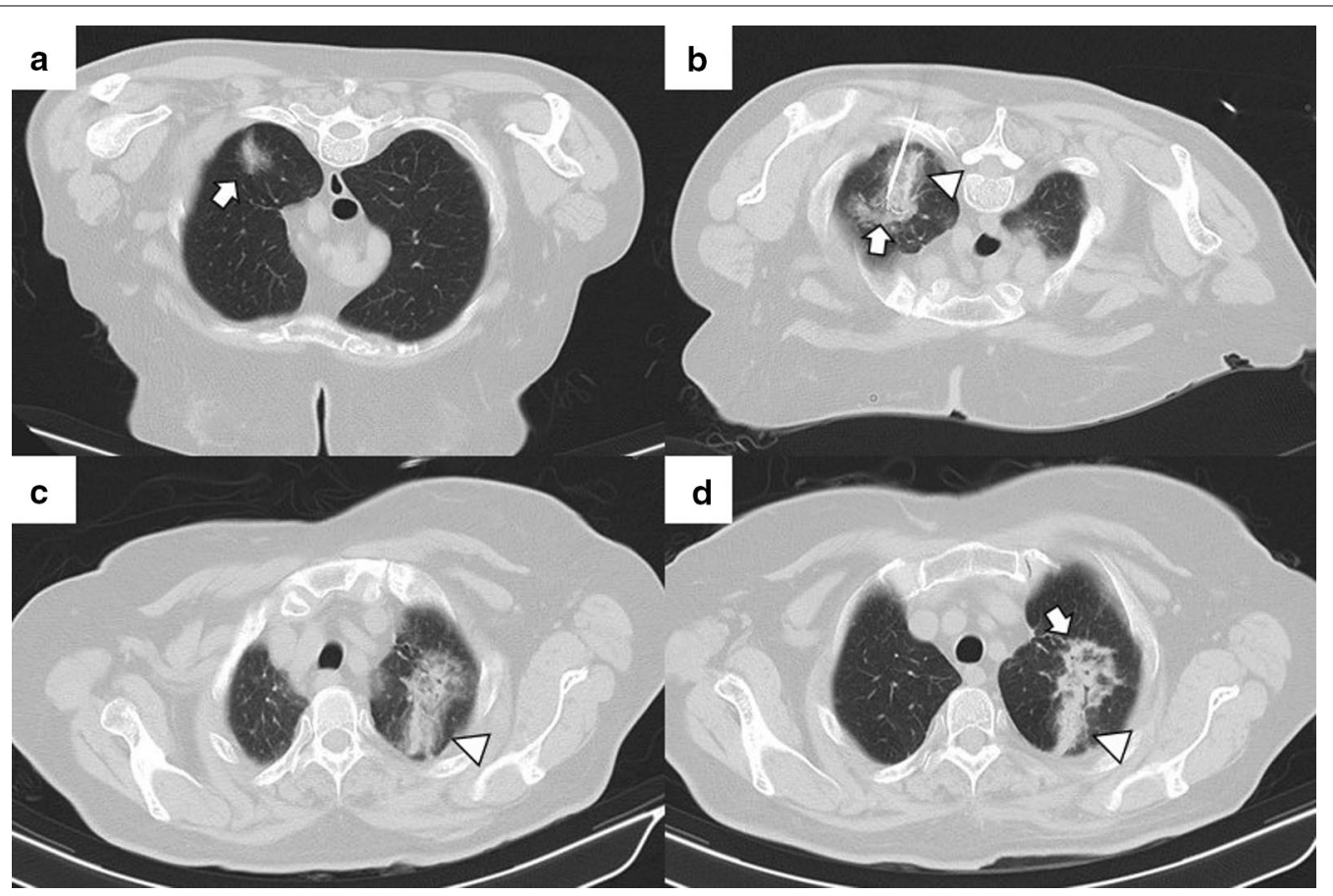

Fig. 7 Mild lung hemorrhage in the path of the ablation probe. $\mathbf{a}, \mathbf{b}$ CT-guided percutaneous RFA with an expandable probe of a stage 1 NSCLC (arrow in $\mathbf{a}$ ). The expandable probe completely covers the tumor in $\mathbf{b}$ (arrow), and the formation of a lung hemorrhage is visible in the probe's path (triangle). $\mathbf{c}$ In the CT scan performed immediately after the procedure, we can observe a mild lung hemorrhage related to the probe's path (triangle). $\mathbf{d}$ The lung hemorrhage remains stable in the CT $24 \mathrm{~h}$ after the procedure, and the patient remains asymptomatic. Note the presence of a ground-glass halo englobing a consolidative center, a suggestive sign of a correct ablative treatment (arrow in $\mathbf{d}$ ) 


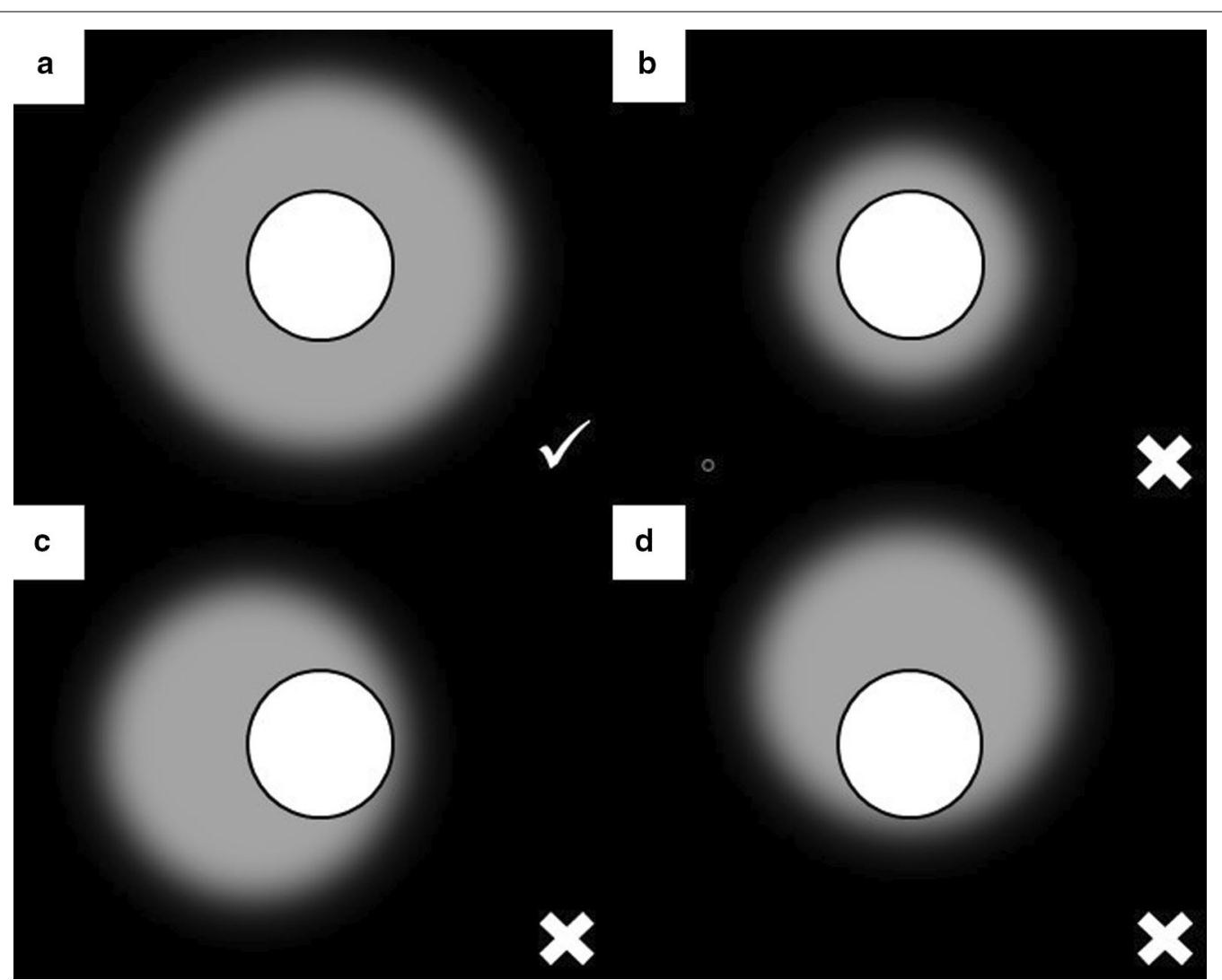

Fig. 8 Schematic illustration demonstrating the ground-glass halo's correct disposition surrounding the treated area. a Proper disposition of the ground-glass halo after ablation lung treatment. The halo must completely surround the tumor and be greater than 5 mm, preferably between 8 and $10 \mathrm{~mm}$. b-d Different forms of incomplete treatment after percutaneous pulmonary ablation as demonstrated by the disposition of the ground-glass halo

should return to regular activity two months after the procedure. The following FDG uptake patterns suggest treatment response: diffuse, peripheral, heterogeneous, and peripheral plus focal at a different site than the initial lesion (Fig. 14). A solitary focal or a diffuse peripheral uptake combined with a focal uptake at the same site of the original lesion suggests tumor progression/recurrence (Fig. 15) [82, 83].

\section{Late-phase ( $>3$ months)}

During the first 3 to 6 months, the treated area should be stable in size. After this period, the zone will progressively decrease in size, reaching a size smaller than that of the original tumor. During this period, the treated area should present a morphology that varies between ovoid, rounded or linear, and, eventually, a lung scar (Figs. 16 and 17). After treatment, the treated area may evolve into five distinct patterns: fibrosis (most common), nodular pattern, cavitation, atelectasis, and local tumor progression. The presence of none of the first four has been shown to predict the occurrence of tumor progression
[75]. However, an increase in the treated area's size after the first three months that persists beyond six months after ablation suggests tumor recurrence [79]. Due to the recovery of microcirculation in the ablation area in the first three months after ablation, there may be an increase compared to the initial or intermediate period, which should gradually decrease in the following three to six months. Nonetheless, at no time should enhancement exceed that of the original tumor (Fig. 18) [48]. After two months, any hypermetabolic activity observed by PETCT within the ablation site suggests tumor progression/ recurrence [83].

\section{Clinical outcomes Stage I NSCLC}

Numerous studies have documented the safety and efficacy of RFA in patients with stage I NSCLC. The first published retrospective studies reported overall survival rates (OS) after RFA treatment at 1-, 2-, 3-, 4-, and 5 -year of $78 \%, 57 \%, 36 \%, 27 \%$, and $27 \%$ and local recurrence rates of $12 \%$ at one year, $18 \%$ at two years, 


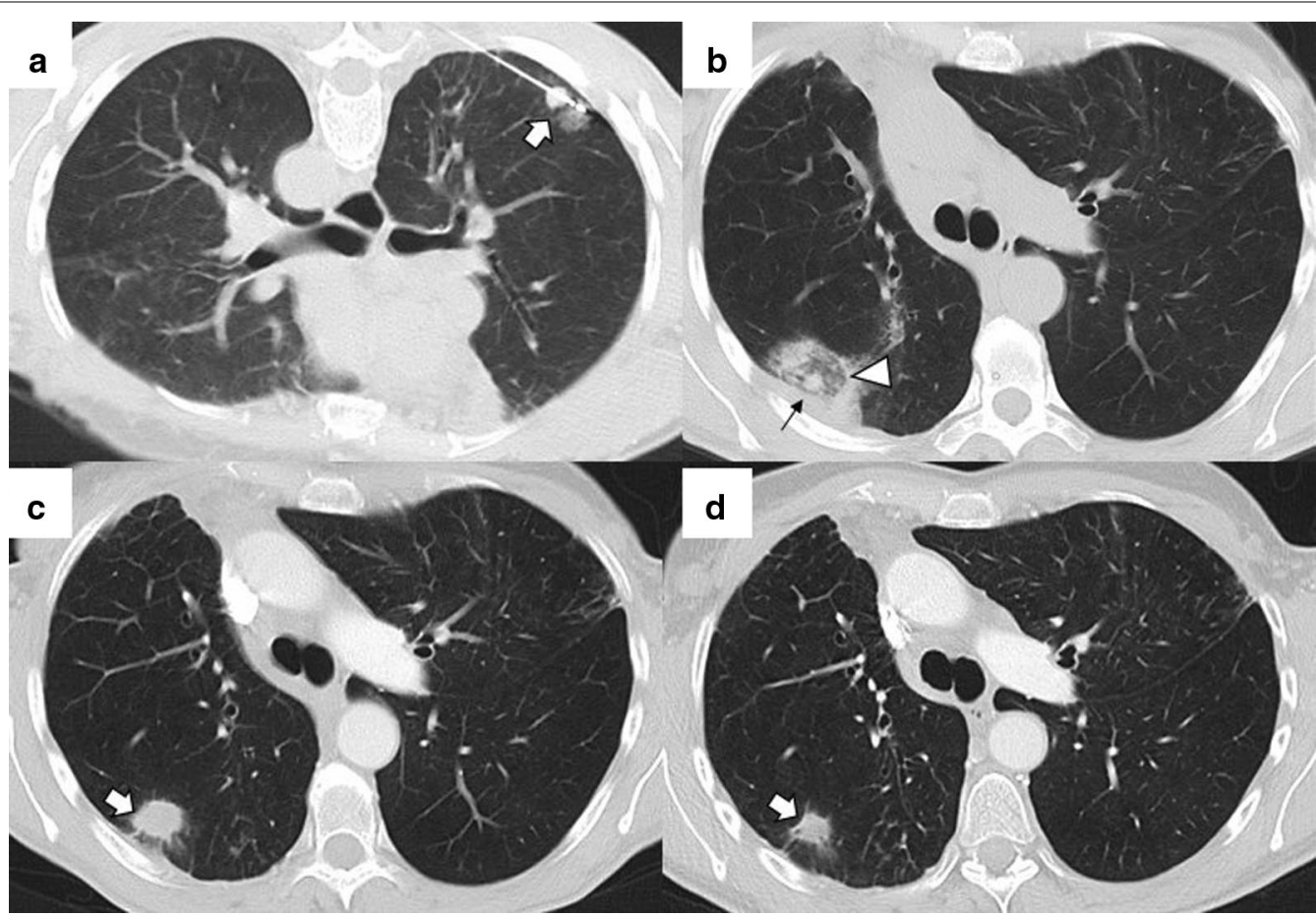

Fig. 9 Radiological findings indicative of successful treatment immediately following image-guided percutaneous lung ablation. a CT-guided MWA with a single straight probe of a stage 1 NSCLC located in the lower right lobe. b We observed a consolidative center (black arrow) surrounded by a peripheral ground-glass halo (triangle) in the area treated in the CT scan performed immediately after completion of the procedure. The combination of these findings is indicative of successful treatment. c Follow-up CT one month after treatment. Note the increase in the size of the treated area compared to A. However, there are no irregular nodular areas nor other signs of tumor persistence. $\mathbf{d}$ CT 6 months after treatment The treated area has decreased in size compared to C, suggesting a successful treatment

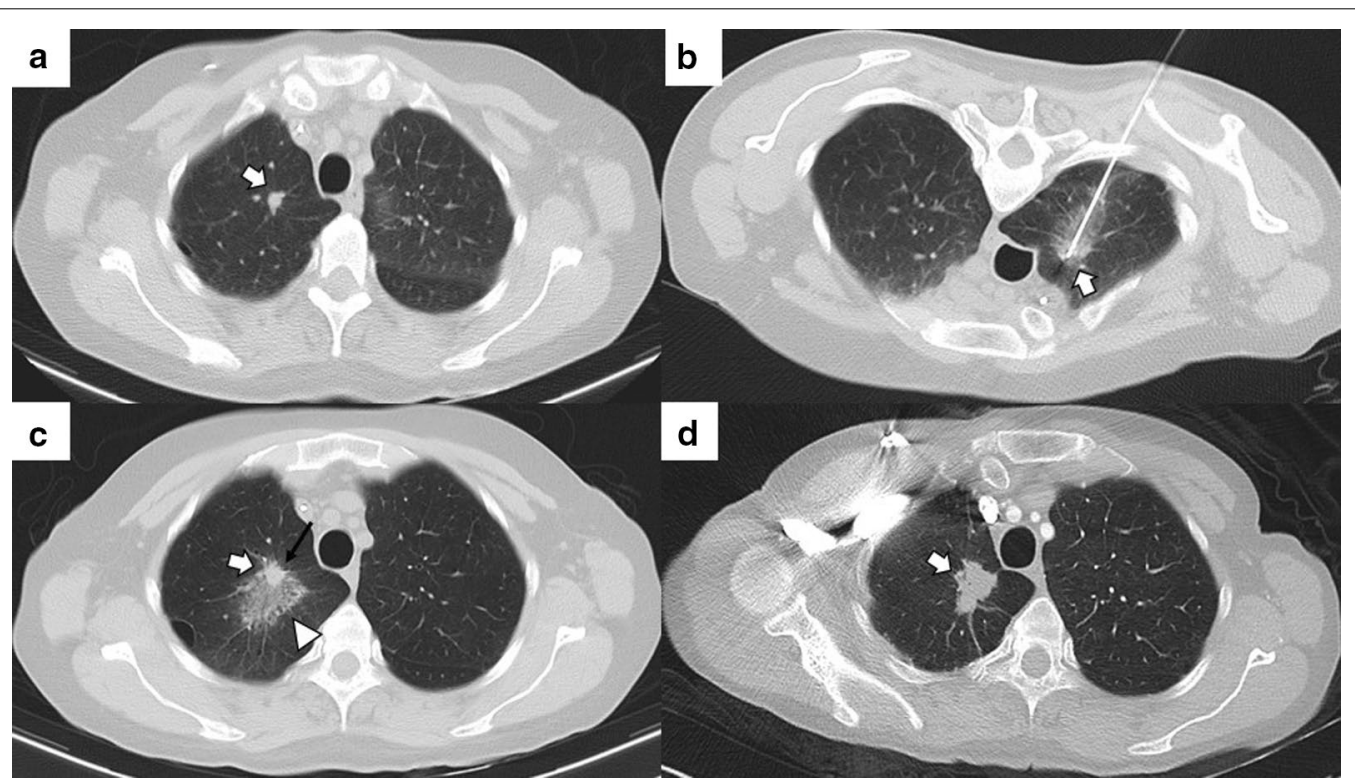

Fig. 10 Tumor persistence after treatment with image-guided percutaneous lung ablation. a Non-enhanced CT showing a single metastatic tumor in the upper right lobe in a patient with rectal carcinoma. $\mathbf{b}$ CT-guided RFA treatment using a straight probe, passing through the center of the tumor. c A non-enhanced CT was performed $24 \mathrm{~h}$ after treatment, showing the treated lesion (thick white arrow) surrounded by a ground-glass halo (triangle). However, the treated tumor's frontmost portion does not present a ground-glass halo (thin black arrow), which may correspond to incomplete treatment. $\mathbf{d}$ Contrast-enhanced CT scan performed three months after treatment shows a considerable increase in the treated lesion, which now presents nodular and irregular borders, consistent with tumor persistence 


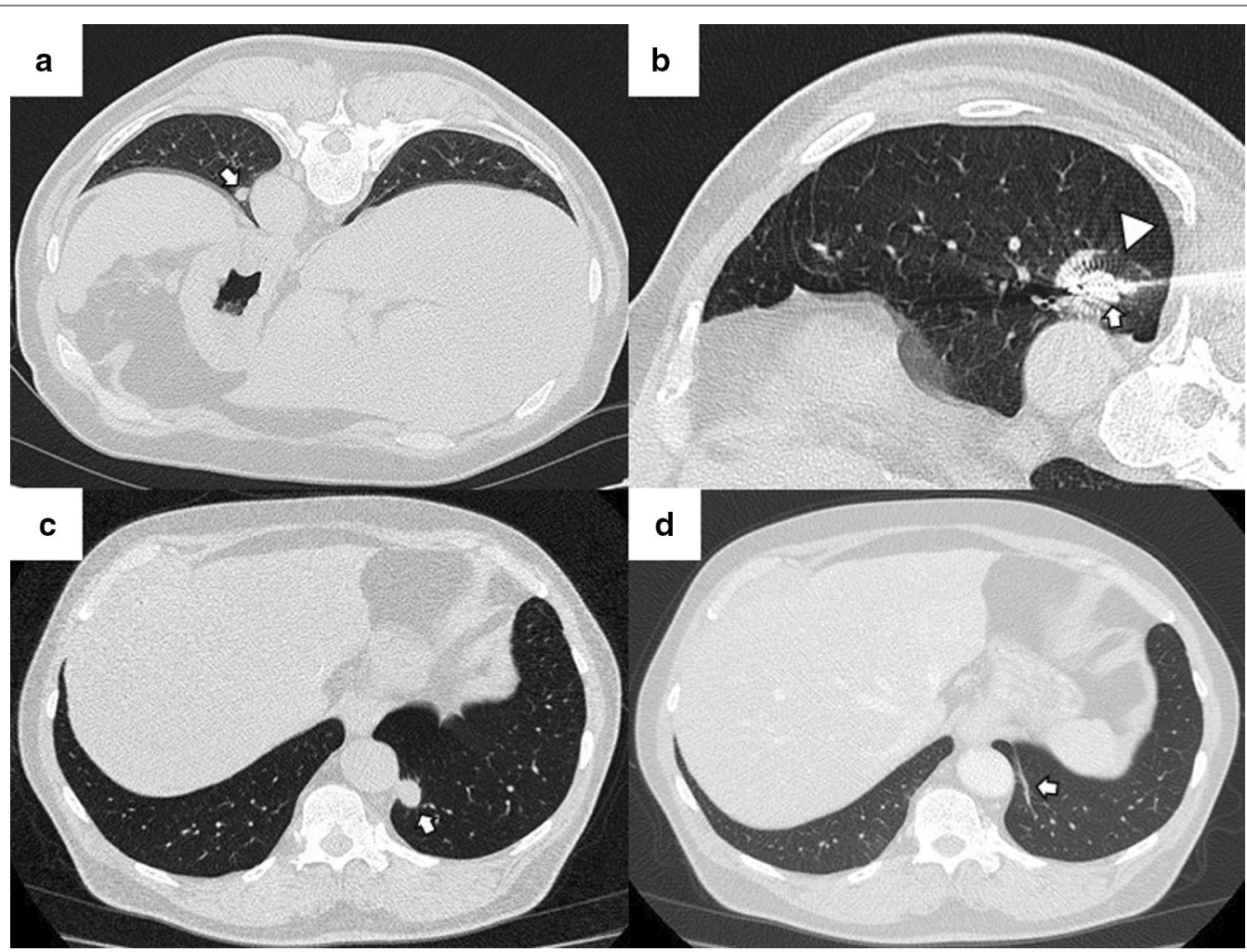

Fig. 11 "Iceball" formation while performing an image-guided percutaneous lung CA. a CT of a patient with oligometastatic disease due to a small cell renal carcinoma with a lesion near the descending thoracic aorta (arrow). b CT-guided CA of this lesion, given the lesion's small size, it was possible to use a single straight probe placed in the center of the lesion (arrow). Note the hypodense halo surrounding the lesion, consistent with the "ice ball" formed during treatment (triangle). c Non-contrast CT scan one month after treatment. The treated area shows a larger size than the original lesion (arrow). However, it is a rounded area of similar size to the image immediately after treatment (not available). $\mathbf{d}$ Non-contrast CT scan six months after treatment. A lung scar is now observed in the treated area, consistent with effective treatment (arrow)

and $21 \%$ at three years, respectively. Furthermore, these early studies already reported that tumors whose diameter was $<3 \mathrm{~cm}$ showed the best results, with a higher rate of recurrence in tumors whose maximum diameter was $>2 \mathrm{~cm}[84,85]$. The first published prospective multicenter trial evaluated 54 patients with stage Ia NSCLC treated with RFA. This study reported OS rates of $86.3 \%$ after one year and $69.8 \%$ at two years, including OS rates of up to $83 \%$ in tumors with a maximum diameter $<2 \mathrm{~cm}$ [74]. A recent prospective multicenter phase II trial involving 32 patients with stage Ia NSCLC not suitable for surgery and treated with RFA showed local control rates of $84.38 \%$ and $81.25 \%$ and OS rates of $91.67 \%$ and $58.33 \%$ at 1 and 3 years. Furthermore, this study reported no significant changes in lung function after treatment [73]. These studies showed that the maximum tumor diameter is the most critical characteristic for predicting technical and therapeutic success. Tumors with a maximum diameter between 2 and $3 \mathrm{~cm}$ seem to be more amenable to successful treatment. Moreover, we can observe a progressive increase in OS rates between early published studies and those more recently conducted. This increase is probably due to a progressive improvement in both the ablation technique and patient selection.

Although not as extensively studied as RFA, MWA is gaining increasing popularity and acceptance in imageguided percutaneous lung ablation. Much like RFA, the first studies published at MWA were noncomparative retrospective studies. Two of the most important reported 1-, 2-, 3-, and 5-year OS rates between 78-89\%, 54-63\%, $39-43 \%$, and $16 \%$ and 1-, 3-, and 5-year local control rates of $96 \%, 64 \%$, and $48 \%[86,87]$. Also, the authors of one of such studies reported a mean time to recurrence at 39.7 months. This last parameter showed a strong correlation with the maximum diameter of the treated tumor. Thus, tumors with a maximum diameter $>3 \mathrm{~cm}$ showed a median time to recurrence of 17.3 months, while those with a maximum diameter of $<3 \mathrm{~cm}$ showed a median time to recurrence of 62.1 months [86, 87]. Another recent retrospective study compared MWA with RFA in 161 patients with lung tumors, of which 41 had a phase 1 


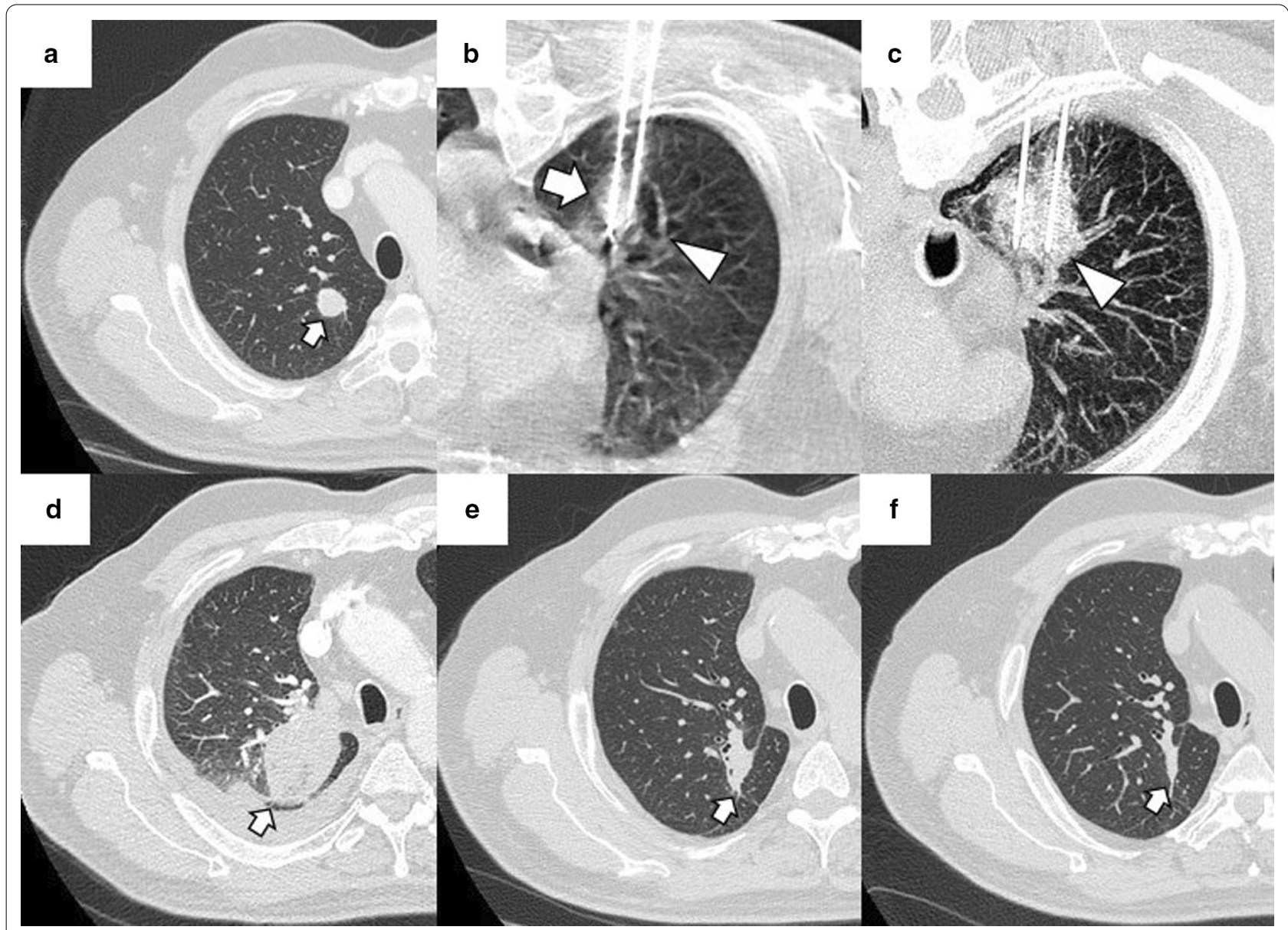

Fig. 12 "Iceball" formation and further evolution to an area of lung hemorrhage in an image-guided percutaneous pulmonary cryoablation. a CT scan performed before ablative treatment, demonstrating a single metastatic lesion from a colon carcinoma in the upper right lobe (arrow). b, c CT-guided CA performed with two straight probes. Note the position of the probes, parallel and at the edges of the lesion. In (b) the ice ball (triangle) is observed surrounding the tumor (arrow). This ice ball was subsequently replaced by a ground-glass halo in (c) (triangle). $\mathbf{d}$ Contrast-enhanced CT scan performed one month after treatment, with a treated area more extensive than the original lesion (arrow). e, f The treated area gradually decreases in size at three (e) and six months (f) after treatment, consistent with successful treatment (arrows)

NSCLC (18 treated with RFA and 23 treated with MWA). This study reported similar efficacy and safety between the two techniques. However, this study fails to specify the recurrence and survival rates segmented by tumor type [25]. No prospective studies comparing both ablative techniques are currently available.

Unlike MWA and RFA, there are currently only a handful of significant studies evaluating the utility of $\mathrm{CA}$ in the treatment of NSCLC. One of the first relevant studies published evaluated retrospectively 45 patients with medically inoperable stage I NSCLC. This study reported a 5-year OS rate of $67.8 \%$ with a 5 -year progression-free survival rate of $87.9 \%$. Local recurrence rate was $36.2 \%$ [88]. Additionally, in a more recent retrospective study, 25 patients with stage I NSCLC treated with CA showed 1 and 3 year OS rates of $100 \%$ and $63 \%$. However, local control rates were $71 \%$ at one year and $37 \%$ at three years, both lower than those reported using MWA or RFA. Like MWA and RFA, the maximum tumor diameter appears to be the most critical predictive parameter. Tumors with a maximum diameter of $>3 \mathrm{~cm}$ are associated with a higher risk of progression [89]. Although these studies may show that CA has similar efficacy to RFA in the treatment of stage I NSCLC, these are retrospective studies with very few patients. Prospective and comparative studies are needed to establish the real value of CA earlystage NSCLC.

In the largest retrospective series published to date, OS rates of thermal ablation and SRT were compared in a sample from the National Cancer Database in the United States. All three lung ablation modalities were considered. Thermal ablation proved to be non-inferior 


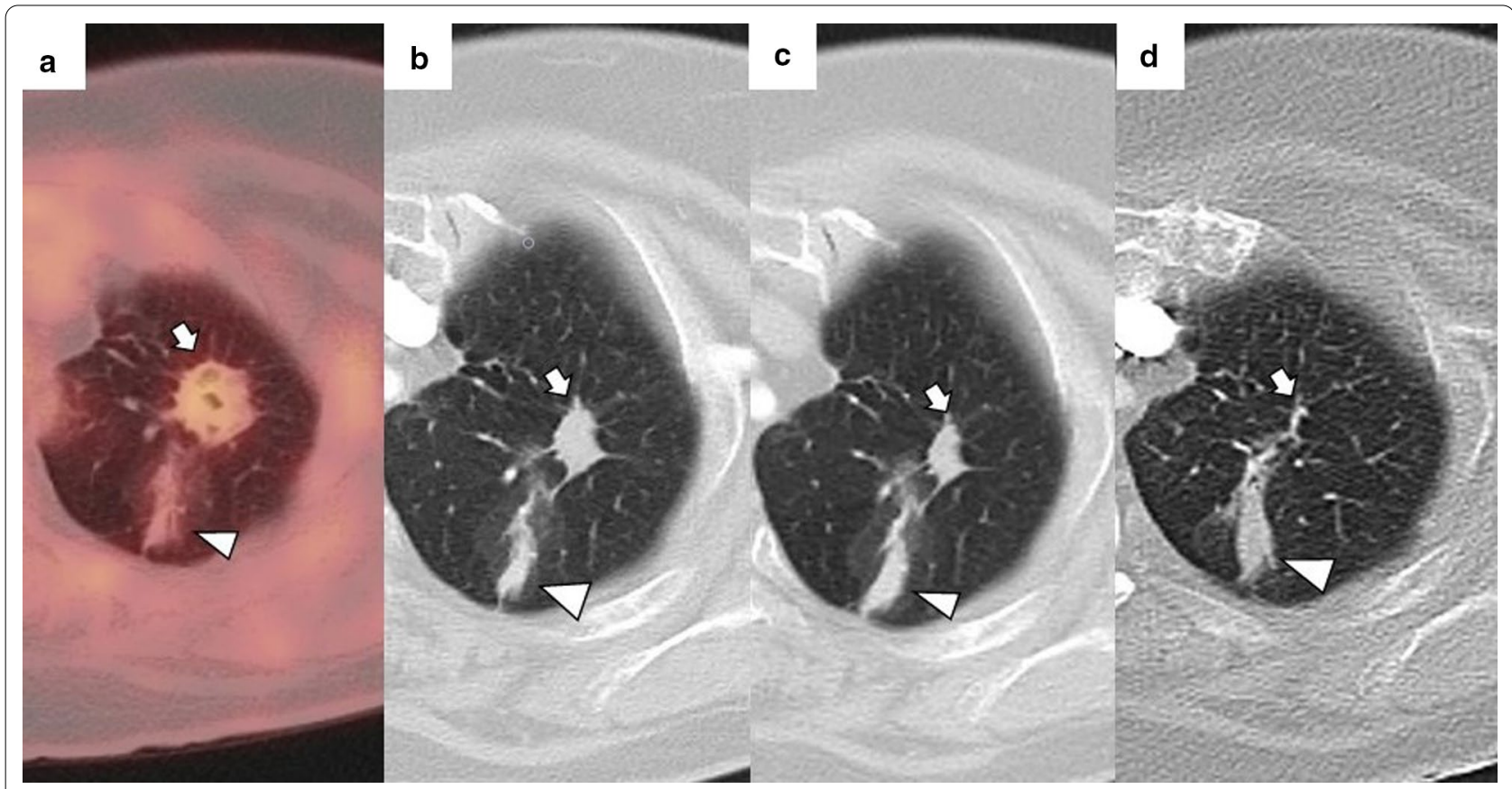

Fig. 13 FDG uptake in a PET/CT one month after image-guided percutaneous lung ablation. a PET-CT acquired after one month of percutaneous lung MWA, showing a growth of the ablative area compared to the pre-treatment CT (Fig. 7-A). It also presented a subtle uptake of FDG within the treated area (arrow). Given the proximity of the treatment, this is probably due to an inflammatory reaction. We also observe a residual scar due to a past probe-path-related lung hemorrhage reported (triangle). b-d We observed a progressive reduction in the size of the ablative area after 3 (b), 6 (c), and 12 months (d) of treatment, finally observing a residual scar (arrows)

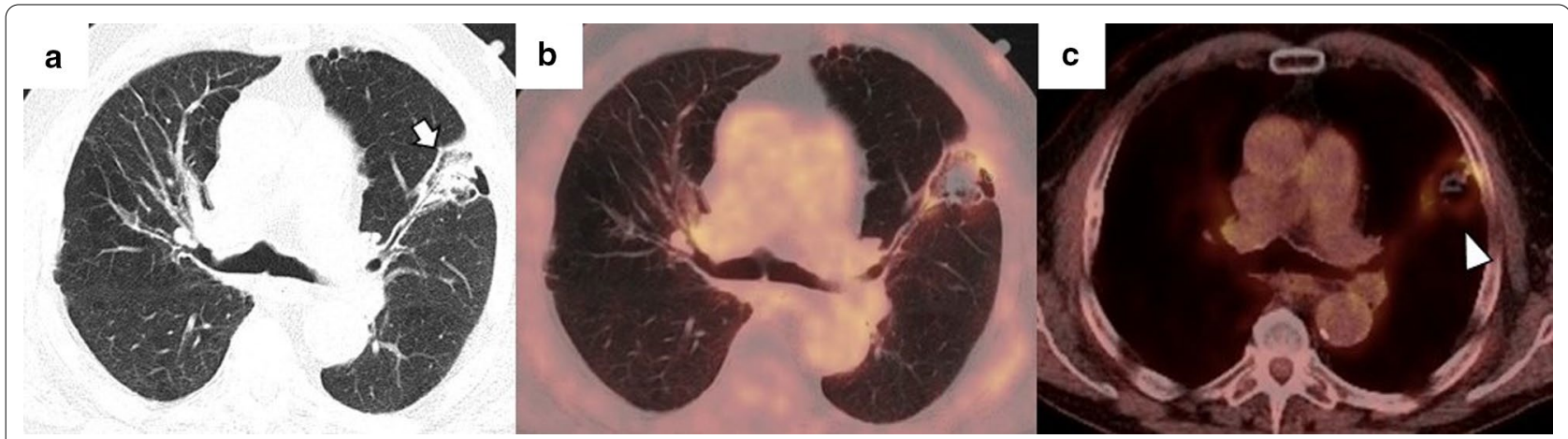

Fig. 14 Peripheral FDG capture pattern on a PET/CT performed two months after image-guided percutaneous lung ablation. a non-contrast CT showing the treated area: a central consolidation surrounded by a peripheral ground-glass opacity with a tendency to consolidate (arrow). b, c PET/ CT demonstrating peripheral FDG uptake of the treated area, a pattern suggestive of response to treatment

compared to SRT. OS rates at 1-, 2-, 3-, and 5-year were $85.4 \%, 65.2 \%, 47.8 \%$ and $24.6 \%$ for thermal ablation and $86.3 \%, 64.5 \%, 45.9 \%$ and $26.1 \%$ for SRT [32].

\section{Alternative indications in NSCLC}

Alternative indications for image-guided percutaneous lung ablation include treatment of local recurrence after treatment with radiotherapy and in combination with chemotherapy at inoperable NSCLC in advanced stages. A retrospective study in which 12 patients with local recurrence of NSCLC after treatment with radiotherapy and chemotherapy received rescue therapy using percutaneous thermal ablation (RFA/MWA) reported a median time to recurrence of 14 months and an OS of 35 months. In such patients, we must consider the increased risk of developing bleeding complications due 


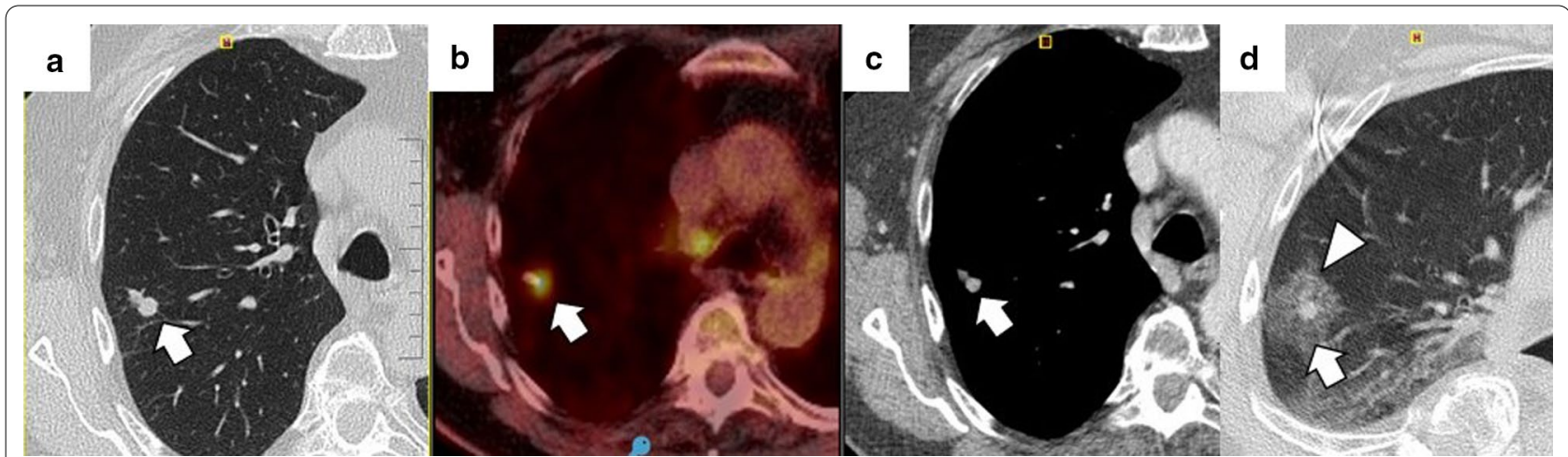

Fig. 15 Diagnosis and retreatment of a tumor recurrence previously treated by image-guided percutaneous pulmonary RFA. a-c Appearance of a solid nodular lesion adjacent to an ablative area in the radiologic control performed six months after a percutaneous lung RFA to treat lung metastasis from a rectal carcinoma (arrow). This lesion exhibits avid FDG (b) and iodine contrast (c) uptake (arrows), and it is consistent with a tumor recurrence at the ablation site. $\mathbf{d}$ The lesion is re-treated using percutaneous lung MWA, with a central consolidative area (arrow) surrounded by a ground-glass halo of more than $5 \mathrm{~mm}$ (triangle). These findings are consistent with comprehensive treatment

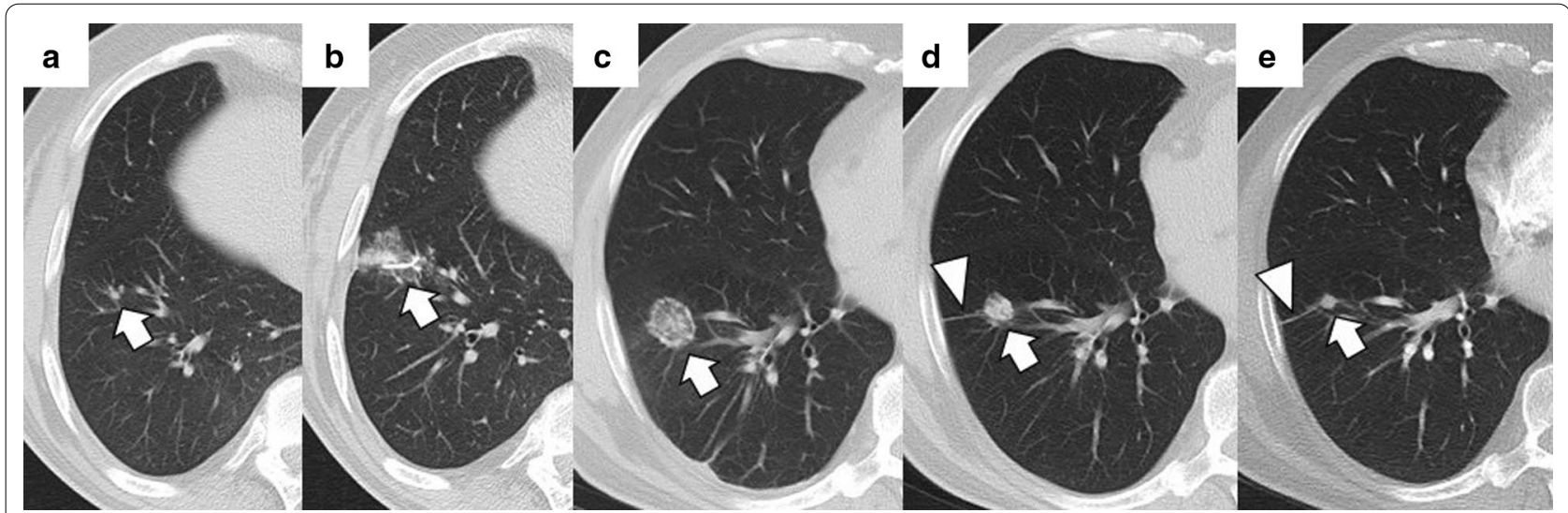

Fig. 16 Evolution towards a nodule pattern after successful treatment with image-guided percutaneous lung ablation. Non-enhanced CT showing a small metastatic lung tumor from a rectal carcinoma in the lower right lobe (arrow in a). The CT scan performed $24 \mathrm{~h}$ after treatment with lung RFA shows a central consolidating area surrounded by a ground-glass opacity at the site of ablation (arrow in $\mathbf{b}$ ). Although the ablative area is larger than the original tumor in the radiologic control performed one month after treatment, it has decreased in size compared to the post-ablative image (arrow in c). After six months of treatment, only a residual consolidation of rounded morphology remains in the treated area (arrow in $\mathbf{d}$ ), with an adjacent lung scar (triangle in $\mathbf{c}, \mathbf{d}$ )

to radiation-associated vasculopathy when treating these patients [40]. Furthermore, a recent prospective noncomparative study that evaluated the utility of percutaneous ablation in patients with stage IIIB or IV NSCLC after treatment with first-line chemotherapy reported a mean local control time of 10.6 months and an OS of 17.7 months [90].

The advent of immunotherapy drugs for lung cancer treatment is one of the most novel developments in recent years in the treatment of NSCLC [27]. In this regard, recently published studies have investigated the combination of percutaneous ablation with immunomodulatory therapy. A prospective randomized study compared the effect of combining CA with Gefitinib, an orally active epidermal growth factor receptorTKI (EGFR-TKI), with Gefitinib alone in patients with advanced NSCLC. This study reported superior partial regression and disease stabilization and decreased disease progression rates in the $\mathrm{CA}+$ Gefitinib group compared to those that received only Gefitinib [35]. Moreover, a prospective controlled study demonstrated the safety and an increase in survival of CA combined with allogenic natural killer (NK) cell immunotherapy for the treatment of advanced NSCLC compared to the control group (CA alone), with no significant increase in adverse effects [91]. 


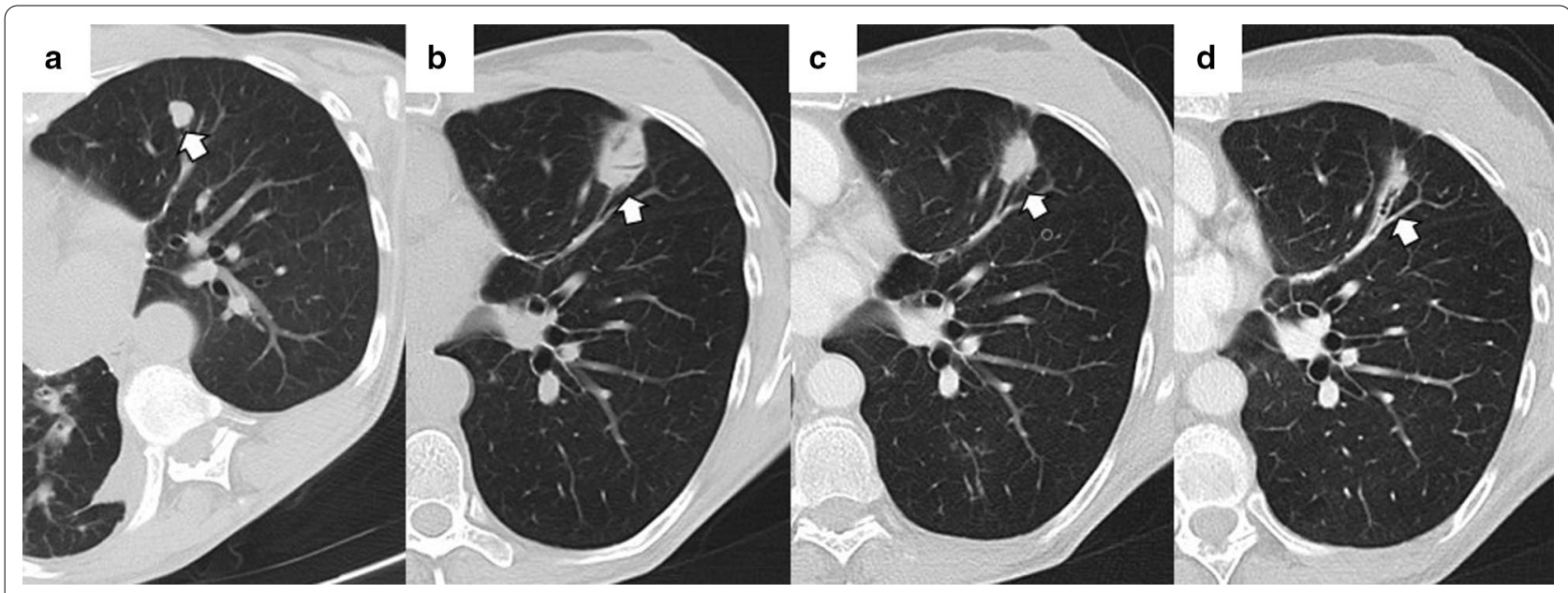

Fig. 17 Imaging follow-up with an evolution towards fibrosis after successful treatment with image-guided percutaneous lung ablation. CT showing a metastatic lung lesion of $<2 \mathrm{~cm}$ due to a small cell renal carcinoma (arrow in $\mathbf{a}$ ). The treated area has grown in size compared to the original tumor in the radiological control after one month of treatment (arrow in b). However, in the radiological follow-up performed following three (c) and six months (d) after treatment, it successively reduces its size until only an area of fibrosis remains (arrow in $\mathbf{d}$ )

\section{Oligometastatic lung disease}

As in the NSCLC, RFA has been the most extensively tested and documented technique in OLD percutaneous ablative treatment. One of the most extensive retrospective studies published to date evaluated 566 patients with 1037 metastases from various primary tumors. This study reported a median OS of 62 months, a 5-year OS of $52 \%$, and local tumor progression rates of $5.9 \%, 8.5 \%$, $10.2 \%$, and $11.0 \% 1-, 2-, 3-$, and 4-year [68]. Also, as with NSCLC, tumors with a maximum diameter $<3 \mathrm{~cm}$ showed improved local tumor response and higher OS. Primary tumor type, disease-free interval, and the presence of more than three lung metastases were also significant variables [68]. The first prospective study to evaluate RFA treatment in patients with OLD (RAPTURE study) reported 1- and 2-year OS rates between 89-92\% and 64-66\% [92]. Furthermore, a recently published retrospective study evaluated 188 patients with lung metastases from colorectal carcinoma treated with RFA. This study reported a median progression-free survival of 6.8 months and an OS of y 52.7 months. Likewise, among the variables that influenced the OS, the most remarkable were: the presence of extrapulmonary metastases and maximum tumor size of $>15 \mathrm{~mm}$ [39]. In the most important (prospective and multicenter) and recently published study on this subject, Hasegawa et al. reported a series of 70 patients with lung metastases from colorectal cancer of $<3 \mathrm{~cm}$ treated with RFA an OS rate at 3 years of $84 \%$, with hardly any complications $(1 \%$ of severe complications). Factors associated with a worse OS include a rectal rather than a colon origin and the absence of chemotherapy [93].
Unlike NSCLC, several published studies have evaluated the value of MWA in OLD. One of the first prospective studies published evaluated 80 patients with unresectable lung metastases treated with MWA. At 12 and 24 months, the OS rates were $91.3 \%$ and $75 \%$. Furthermore, as in RFA, size was the main predictor of therapeutic success, with incomplete ablation more likely in lesions $>3 \mathrm{~cm}$. There was also a better technical success in peripheral lesions than those close to the pulmonary hilum [94]. Another retrospective study compared MWA, RFA, and LITT results in 109 patients with lung metastases from colorectal carcinoma. Local tumor control rates were $68.0 \%$ for LITT, $69.2 \%$ for RFA, and $88.3 \%$ for MWA, with statistically significant differences between MWA and the other two techniques. The median time of local tumor progression published for each technique was 10.4 months for LITT, 7.2 months for RFA, and 7.5 months for MWA, as well as OS of 22.1 months for LITT, 24.2 months for RFA, and 32.8 months for MWA [95]. A much recent published meta-analysis compared the results obtained between RFA and MWA in the ablative treatment of pulmonary metastases, with a total inclusion of 3,432 patients. Patients treated with RFA presented an OS and a survival rate at 1,- 2,- 3 , and 5 years higher than the MWA branch, reporting similar local recurrence rates between the two techniques. However, given the studies' heterogeneity, the high probability of publication bias, especially in the RFA branch, and a lower number of patients in the MWA group, one technique's superiority over the other could not be definitively concluded [16]. In conclusion, MWA has proven to be a technique at least as effective and safe 


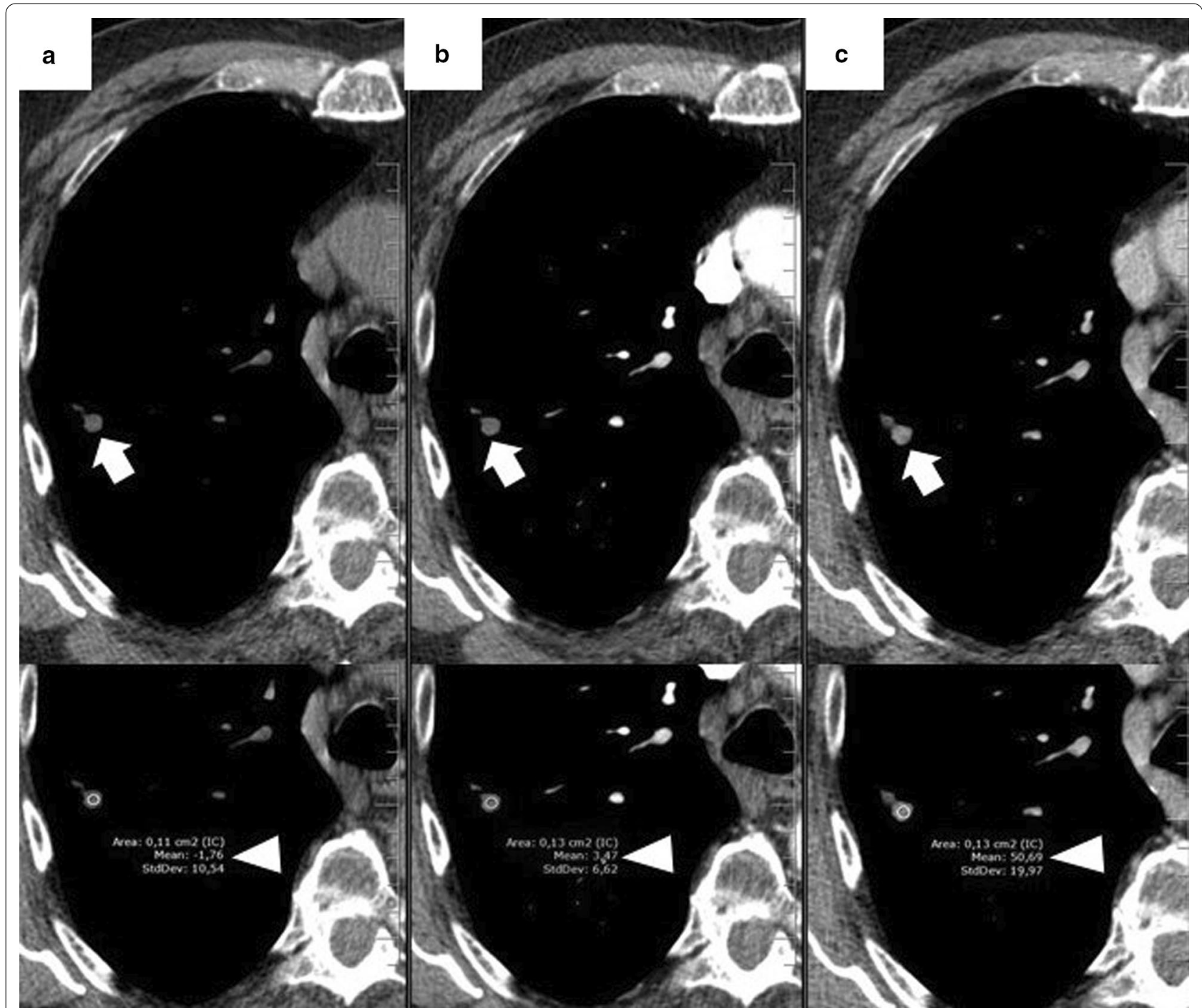

Fig. 18 Contrast enhancement in a nodule adjacent to the treated area after image-guided percutaneous lung ablation. a Unenhanced CT showing a nodular lesion adjacent to an area treated with a lung ablation (arrow). b, c The lesion enhances after administering intravenous iodine contrast (arrows), successively increasing HU between the arterial and venous phase (triangles). These findings are compatible with tumor recurrence

as RFA in OLD's ablative treatment. However, prospective randomized studies comparing both techniques are still needed.

Two single-arm prospective multicenter studies have demonstrated the efficacy and safety of CA in treating pulmonary metastases. In 2015, the ECLIPSE study included 40 patients with 60 lung metastases treated with CA, with a follow-up of at least 12 months. This study applied strict inclusion criteria. Local tumor control rates were $96.6 \%$ and $94.2 \%$ at 6 and 12 months, respectively. The one-year overall survival rate was $97.5 \%$ [96]. The SOLSTICE study, a multicenter, phase II, prospective, single-arm study involving 128 patients with 224 lung metastases treated with CA, recently published its results. The patients' follow-up in this study was from 12 to 24 months, and the inclusion criteria were laxer compared to the ECLIPSE study. After the first ablation, the response rate without local recurrence was $85.1 \%$ at 12 months and $77.2 \%$ at 24 months. After a second CA for local recurrence treatment, the response rate without local recurrence was $91.1 \%$ at 12 months and $84.4 \%$ at 24 months. The mean OS rate at 12 and 24 months was $97.6 \%$ and $86.6 \%$ [97]. The results of both studies demonstrated the efficacy and safety of this technique in the treatment of OLD. Studies comparing CA with the other 
available ablative techniques, as well as with metastasectomy, should be conducted.

All available evidence recommends, regardless of the ablative technique selected, the need for patient selection guided by strict pre-established clinical and radiological criteria to avoid unnecessary treatment and obtain local tumor progression and OS rates similar to those offered by surgical metastasectomy. Moreover, to design therapeutic algorithms in OLD treatment, it is necessary to conduct prospective and randomized studies that compare percutaneous ablation in its different modalities with surgical treatment.

\section{Conclusions}

Image-guided percutaneous lung ablation has proven to be a safe and effective treatment modality in patients with early-stage NSCLC or OLD. As there are no specific protocols established in handling these patients, there must be a careful patient selection to avoid unnecessary treatments and undesired results. In this regard, size is the most critical factor in predicting ablative treatment success. It is also essential to know the radiological findings observed in the treated area during treatment and follow-up. When choosing among the available ablative modalities, the available scientific evidence indicates that their efficacy and safety are comparable. Therefore, selection depends on the specific characteristics of the tumor and the patient. Finally, prospective, comparative, and randomized studies between these techniques, SBRT, and surgery are pending to define and improve patient selection.

\section{Abbreviations \\ CA: Cryoablation; CBCT: Cone-beam CT-guidance; CCT: Conventional computed tomography-guided technique; CT: Computed tomography; CTF: CT-fluoroscopy guided technique; ECOG: Eastern Cooperative Oncology Group; EGFR: Epidermal growth factor receptor; FDG: Fluorodeoxyglucose; IRE: Irreversible electroporation; LITT: Laser-induced thermotherapy; MWA: Microwave ablation; NK: Natural killer; NSCLC: Non-small cell lung carcinoma; OLD: Oligometastatic lung disease; OS: Overall survival; PET/CT: Positron emis- sion tomography; RFA: Radiofrequency ablation; SRT: Stereotactic radiation therapy; TKI: Tyrosine kinase inhibitors.}

\section{Authors' contributions}

All authors contributed equally to this manuscript. All authors read and approved the final manuscript.

\section{Funding}

This study was not supported by any funding.

\section{Availability of data and materials}

Data sharing is not applicable to this article as no datasets were generated or analyzed during the current study.

\section{Declarations}

Ethics approval and consent to participate Not applicable.
Consent for publication

Not applicable.

\section{Competing interests}

The authors declare that they have no competing interests.

\section{Author details}

'Department of Radiology, CDI, Hospital Clínic, University of Barcelona, Barcelona, Spain. ${ }^{2}$ Department of Radiology, The Netherlands Cancer Institute, Amsterdam, The Netherlands. ${ }^{3}$ Department of Nuclear Medicine, CDI, Hospital Clínic, University of Barcelona, Barcelona, Spain. ${ }^{4}$ Department of Anesthesiology, Hospital Clínic, University of Barcelona, Barcelona, Spain.

Received: 30 December 2020 Accepted: 9 April 2021

Published online: 29 April 2021

\section{References}

1. Bray F, Ferlay J, Soerjomataram I et al (2018) Global cancer statistics 2018: GLOBOCAN estimates of incidence and mortality worldwide for 36 cancers in 185 countries. CA Cancer J Clin 68:394-424

2. Mohammed TL, Chowdhry A, Reddy GP et al (2011) ACR Appropriateness Criteria ${ }^{\circledR}$ screening for pulmonary metastases. J Thorac Imaging 26:W1-3

3. Postmus PE, Kerr KM, Oudkerk M et al (2017) Early and locally advanced non-small-cell lung cancer (NSCLC): ESMO Clinical Practice Guidelines for diagnosis, treatment and follow-up. Ann Oncol 28:iv1-iv21

4. Detterbeck FC, Chansky K, Groome P et al (2016) The IASLC lung cancer staging project: methodology and validation used in the development of proposals for revision of the stage classification of NSCLC in the forthcoming (eighth) edition of the TNM classification of lung cancer. J Thorac Oncol 11:1433-1446

5. Fernando HC, Landreneau RJ, Mandrekar SJ et al (2014) Impact of brachytherapy on local recurrence rates after sublobar resection: results from ACOSOG Z4032 (Alliance), a phase III randomized trial for high-risk operable non-small-cell lung cancer. J Clin Oncol 32:2456-2462

6. Van Cutsem E, Cervantes A, Adam R et al (2016) ESMO consensus guidelines for the management of patients with metastatic colorectal cancer. Ann Oncol 27:1386-1422

7. Treasure T, Milošević M, Fiorentino F et al (2014) Pulmonary metastasectomy: what is the practice and where is the evidence for effectiveness. Thorax 69:946-949

8. Cheung FP, Alam NZ, Wright GM (2019) The past, present and future of pulmonary metastasectomy: a review article. Ann Thorac Cardiovasc Surg 25:129-141

9. Mouli SK, Kurilova I, Sofocleous CT et al (2017) The role of percutaneous image-guided thermal ablation for the treatment of pulmonary malignancies. AJR Am J Roentgenol 209:740-751

10. Palussière J, Catena V, Buy X (2017) Percutaneous thermal ablation of lung tumors - radiofrequency, microwave and cryotherapy: Where are we going. Diagn Interv Imaging 98:619-625

11. Seror $O$ (2015) Ablative therapies: Advantages and disadvantages of radiofrequency, cryotherapy, microwave and electroporation methods, or how to choose the right method for an individual patient. Diagn Interv Imaging 96:617-624

12. Li G, Xue M, Chen W et al (2018) Efficacy and safety of radiofrequency ablation for lung cancers: a systematic review and meta-analysis. Eur J Radiol 100:92-98

13. Healey TT, March BT, Baird G et al (2017) Microwave ablation for lung neoplasms: a retrospective analysis of long-term results. J Vasc Interv Radiol 28:206-211

14. Inoue M, Nakatsuka S, Jinzaki M (2014) Cryoablation of early-stage primary lung cancer. Biomed Res Int 2014:521691

15. Ricke J, Jürgens JH, Deschamps F et al (2015) Irreversible electroporation (IRE) fails to demonstrate efficacy in a prospective multicenter phase II trial on lung malignancies: the ALICE trial. Cardiovasc Intervent Radiol 38:401-408

16. Vogl TJ, Eckert R, Naguib NN et al (2016) Thermal ablation of colorectal lung metastases: retrospective comparison among laser-induced 
thermotherapy, radiofrequency ablation, and microwave ablation. AJR Am J Roentgenol 207:1340-1349

17. Ahmed M, Liu Z, Afzal KS et al (2004) Radiofrequency ablation: effect of surrounding tissue composition on coagulation necrosis in a canine tumor model. Radiology 230:761-767

18. Ihara H, Gobara H, Hiraki T et al (2016) Radiofrequency Ablation of Lung Tumors Using a Multitined Expandable Electrode: Impact of the Electrode Array Diameter on Local Tumor Progression. J Vasc Interv Radiol 27:87-95

19. Skonieczki BD, Wells C, Wasser EJ et al (2011) Radiofrequency and microwave tumor ablation in patients with implanted cardiac devices: is it safe. Eur J Radiol 79:343-346

20. Robert Sheu Y, Hong K (2013) Percutaneous lung tumor ablation. Tech Vasc Interv Radiol 16:239-252

21. Wright AS, Sampson LA, Warner TF et al (2005) Radiofrequency versus microwave ablation in a hepatic porcine model. Radiology 236:132-139

22. Simon CJ, Dupuy DE, Mayo-Smith WW (2005) Microwave ablation: principles and applications. Radiographics 25(Suppl 1):S69-83

23. Vogl TJ, Farshid P, Naguib NN et al (2014) Thermal ablation of liver metastases from colorectal cancer: radiofrequency, microwave and laser ablation therapies. Radiol Med 119:451-461

24. Wolf FJ, Grand DJ, Machan JT et al (2008) Microwave ablation of lung malignancies: effectiveness, CT findings, and safety in 50 patients. Radiology $247: 871-879$

25. Aufranc V, Farouil G, Abdel-Rehim M et al (2019) Percutaneous thermal ablation of primary and secondary lung tumors: Comparison between microwave and radiofrequency ablation. Diagn Interv Imaging 100:781-791

26. Cazzato RL, Garnon J, Ramamurthy N et al (2016) Percutaneous imageguided cryoablation: current applications and results in the oncologic field. Med Oncol 33:140

27. Aarts BM, Klompenhouwer EG, Rice SL et al (2019) Cryoablation and immunotherapy: an overview of evidence on its synergy. Insights Imaging 10:53

28. Littrup PJ, Mody A, Sparschu R et al (1994) Prostatic cryotherapy: ultrasonographic and pathologic correlation in the canine model. Urology 44:175-183 (discussion 183-184).

29. Hinshaw JL, Lee FT, Laeseke PF et al (2010) Temperature isotherms during pulmonary cryoablation and their correlation with the zone of ablation. J Vasc Interv Radiol 21:1424-1428

30. Eiken PW, Welch BT (2019) Cryoablation of lung metastases: review of recent literature and ablation technique. Semin Intervent Radiol 36:319-325

31. Sofocleous CT, Sideras P, Petre EN et al (2011) Ablation for the management of pulmonary malignancies. AJR Am J Roentgenol 197:W581-W589

32. Uhlig J, Ludwig JM, Goldberg SB et al (2018) Survival rates after thermal ablation versus stereotactic radiation therapy for stage 1 non-small cell lung cancer: a national cancer database study. Radiology 289:862-870

33. Ager BJ, Wells SM, Gruhl JD et al (2019) Stereotactic body radiotherapy versus percutaneous local tumor ablation for early-stage non-small cell lung cancer. Lung Cancer 138:6-12

34. Moussa AM, Ziv E, Solomon SB, Camacho JC (2019) Microwave ablation in primary lung malignancies. Semin Intervent Radiol 36:326-333

35. Gu XY, Jiang Z, Fang W (2011) Cryoablation combined with molecular target therapy improves the curative effect in patients with advanced non-small cell lung cancer. J Int Med Res 39:1736-1743

36. Steinke K, Glenn D, King J et al (2004) Percutaneous imaging-guided radiofrequency ablation in patients with colorectal pulmonary metastases: 1-year follow-up. Ann Surg Oncol 11:207-212

37. King J, Glenn D, ClarkW et al (2004) Percutaneous radiofrequency ablation of pulmonary metastases in patients with colorectal cancer. Br J Surg 91:217-223

38. Dupuy DE, Zagoria RJ, Akerley W, Mayo-Smith WW, Kavanagh PV, Safran H (2000) Percutaneous radiofrequency ablation of malignancies in the lung. AJR Am J Roentgenol 174:57-59

39. Hiyoshi Y, Miyamoto Y, Kiyozumi Y et al (2019) CT-guided percutaneous radiofrequency ablation for lung metastases from colorectal cancer. Int J Clin Oncol 24:288-295

40. Cheng M, Fay M, Steinke K (2016) Percutaneous CT-guided thermal ablation as salvage therapy for recurrent non-small cell lung cancer after external beam radiotherapy: A retrospective study. Int J Hyperthermia 32:316-323
41. Hiraki T, Gobara H, Fujiwara $\mathrm{H}$ et al (2013) Lung cancer ablation: complications. Semin Intervent Radiol 30:169-175

42. Venturini M, Cariati M, Marra P, Masala S, Pereira PL, Carrafiello G (2020) CIRSE standards of practice on thermal ablation of primary and secondary lung tumours. Cardiovasc Intervent Radiol 43:667-683

43. Pua BB, Thornton RH, Solomon SB (2010) Ablation of pulmonary malignancy: current status. J Vasc Interv Radiol 21:S223-S232

44. Patel IJ, Rahim S, Davidson JC et al (2019) Society of interventional radiology consensus guidelines for the periprocedural management of thrombotic and bleeding risk in patients undergoing percutaneous image-guided interventions-part II: recommendations: endorsed by the canadian association for interventional radiology and the cardiovascular and interventional radiological society of Europe. J Vasc Interv Radiol 30:1168-1184.e1

45. Jaffe TA, Raiff D, Ho LM, Kim CY (2015) Management of anticoagulant and antiplatelet medications in adults undergoing percutaneous interventions. AJR Am J Roentgenol 205:421-428

46. Chehab MA, Thakor AS, Tulin-Silver S et al (2018) Adult and pediatric antibiotic prophylaxis during vascular and IR procedures: a society of interventional radiology practice parameter update endorsed by the cardiovascular and interventional radiological society of europe and the canadian association for interventional radiology. J Vasc Interv Radiol 29:1483-1501.e2

47. Hinkelbein J, Lamperti M, Akeson J et al (2018) European Society of Anaesthesiology and European Board of Anaesthesiology guidelines for procedural sedation and analgesia in adults. Eur J Anaesthesiol 35:6-24

48. Abtin F, De Baere T, Dupuy DE et al (2019) Updates on current role and practice of lung ablation. J Thorac Imaging 34:266-277

49. Kim R (2018) Effects of surgery and anesthetic choice on immunosuppression and cancer recurrence. J Transl Med 16:8

50. Yasui K, Kanazawa S, Sano Y et al (2004) Thoracic tumors treated with CT-guided radiofrequency ablation: initial experience. Radiology $231: 850-857$

51. Rose SC (2008) Radiofrequency ablation of pulmonary malignancies. Semin Respir Crit Care Med 29:361-383

52. Hoffmann RT, Jakobs TF, Lubienski A et al (2006) Percutaneous radiofrequency ablation of pulmonary tumors-is there a difference between treatment under general anaesthesia and under conscious sedation. Eur J Radiol 59:168-174

53. Zanca F, Jacobs A, Crijns W et al (2014) Comparison of measured and estimated maximum skin doses during CT fluoroscopy lung biopsies. Med Phys 41:073901

54. Yang K, Ganguli S, DeLorenzo MC et al (2018) Procedure-specific CT dose and utilization factors for CT-guided interventional procedures. Radiology 289:150-157

55. Chintapalli KN, Montgomery RS, Hatab M et al (2012) Radiation dose management: part 1, minimizing radiation dose in CT-guided procedures. AJR Am J Roentgenol 198:W347-W351

56. Prosch H, Stadler A, Schilling M et al (2012) CT fluoroscopy-guided vs. multislice CT biopsy mode-guided lung biopsies: accuracy, complications and radiation dose. Eur J Radiol 81:1029-1033

57. Matsui Y, Hiraki T, Gobara H et al (2016) Radiation exposure of interventional radiologists during computed tomography fluoroscopy-guided renal cryoablation and lung radiofrequency ablation: direct measurement in a clinical setting. Cardiovasc Intervent Radiol 39:894-901

58. Fu YF, Li GC, Cao W et al (2020) Computed tomography fluoroscopyguided versus conventional computed tomography-guided lung biopsy: a systematic review and meta-analysis. J Comput Assist Tomogr 44:571-577

59. Jin KN, Park CM, Goo JM et al (2010) Initial experience of percutaneous transthoracic needle biopsy of lung nodules using C-arm cone-beam CT systems. Eur Radiol 20:2108-2115

60. Cazzato RL, Battistuzzi JB, Catena V et al (2015) Cone-beam computed tomography (CBCT) versus $\mathrm{CT}$ in lung ablation procedure: which is faster. Cardiovasc Intervent Radiol 38:1231-1236

61. Rotolo N, Floridi C, Imperatori A et al (2016) Comparison of cone-beam CT-guided and CT fluoroscopy-guided transthoracic needle biopsy of lung nodules. Eur Radiol 26:381-389 
62. Smith JC, Jin DH, Watkins GE et al (2011) Ultra-low-dose protocol for CTguided lung biopsies. J Vasc Interv Radiol 22:431-436

63. Hohl C, Suess C, Wildberger JE et al (2008) Dose reduction during CT fluoroscopy: phantom study of angular beam modulation. Radiology 246:519-525

64. Joemai RM, Zweers D, Obermann WR et al (2009) Assessment of patient and occupational dose in established and new applications of MDCT fluoroscopy. AJR Am J Roentgenol 192:881-886

65. Garnon J, Koch G, Ramamurthy N et al (2016) A pitfall of cryoadhesional displacement during cryoablation of lung metastasis to require modification of triple-freeze protocol. Cardiovasc Intervent Radiol 39:960-964

66. Garnon J, Cazzato RL, Caudrelier J et al (2019) Adjunctive thermoprotection during percutaneous thermal ablation procedures: review of current techniques. Cardiovasc Intervent Radiol 42:344-357

67. Palussière J, Gómez F, Cannella M et al (2012) Single-session radiofrequency ablation of bilateral lung metastases. Cardiovasc Intervent Radiol 35:852-859

68. de Baère T, Aupérin A, Deschamps F et al (2015) Radiofrequency ablation is a valid treatment option for lung metastases: experience in 566 patients with 1037 metastases. Ann Oncol 26:987-991

69. Hiraki T, Tajiri N, Mimura H et al (2006) Pneumothorax, pleural effusion, and chest tube placement after radiofrequency ablation of lung tumors: incidence and risk factors. Radiology 241:275-283

70. Alberti N, Buy X, Frulio N et al (2016) Rare complications after lung percutaneous radiofrequency ablation: Incidence, risk factors, prevention and management. Eur J Radiol 85:1181-1191

71. Hinshaw JL, Lubner MG, Ziemlewicz TJ, Lee FT, Brace CL (2014) Percutaneous tumor ablation tools: microwave, radiofrequency, or cryoablationwhat should you use and why. Radiographics 34:1344-1362

72. Wang H, Littrup PJ, Duan Y, Zhang Y, Feng H, Nie Z (2005) Thoracic masses treated with percutaneous cryotherapy: initial experience with more than 200 procedures. Radiology 235:289-298

73. Palussière J, Chomy F, Savina M et al (2018) Radiofrequency ablation of stage IA non-small cell lung cancer in patients ineligible for surgery: results of a prospective multicenter phase II trial. J Cardiothorac Surg 13:91

74. Dupuy DE, Fernando HC, Hillman S et al (2015) Radiofrequency ablation of stage IA non-small cell lung cancer in medically inoperable patients: results from the American College of Surgeons Oncology Group Z4033 (Alliance) trial. Cancer 121:3491-3498

75. Palussière J, Marcet B, Descat E et al (2011) Lung tumors treated with percutaneous radiofrequency ablation: computed tomography imaging follow-up. Cardiovasc Intervent Radiol 34:989-997

76. Anderson EM, Lees WR, Gillams AR (2009) Early indicators of treatment success after percutaneous radiofrequency of pulmonary tumors. Cardiovasc Intervent Radiol 32:478-483

77. de Baère T, Palussière J, Aupérin A et al (2006) Midterm local efficacy and survival after radiofrequency ablation of lung tumors with minimum follow-up of 1 year: prospective evaluation. Radiology 240:587-596

78. Yoo DC, Dupuy DE, Hillman SL et al (2011) Radiofrequency ablation of medically inoperable stage IA non-small cell lung cancer: are early posttreatment PET findings predictive of treatment outcome. AJR Am J Roentgenol 197:334-340

79. Ito N, Nakatsuka S, Inoue M et al (2012) Computed tomographic appearance of lung tumors treated with percutaneous cryoablation. J Vasc Interv Radiol 23:1043-1052

80. Chheang S, Abtin F, Guteirrez A, Genshaft S, Suh R (2013) Imaging features following thermal ablation of lung malignancies. Semin Intervent Radiol 30:157-168

81. Planché O, Teriitehau C, Boudabous S et al (2013) In vivo evaluation of lung microwave ablation in a porcine tumor mimic model. Cardiovasc Intervent Radiol 36:221-228
82. Lafuente S, Fuster D, Arguis P et al (2016) Dual time-point (18)F-FDG PET/ $\mathrm{CT}$ to assess response to radiofrequency ablation of lung metastases. Rev Esp Med Nucl Imagen Mol 35:226-231

83. Singnurkar A, Solomon SB, Gönen M, Larson SM, Schöder H (2010) 18F-FDG PET/CT for the prediction and detection of local recurrence after radiofrequency ablation of malignant lung lesions. J Nucl Med 51:1833-1840

84. Simon CJ, Dupuy DE, DiPetrillo TA et al (2007) Pulmonary radiofrequency ablation: long-term safety and efficacy in 153 patients. Radiology 243:268-275

85. Palussiere J, Lagarde P, Aupérin A, Deschamps F, Chomy F, de Baere T (2015) Percutaneous lung thermal ablation of non-surgical clinical NO non-small cell lung cancer: results of eight years' experience in 87 patients from two centers. Cardiovasc Intervent Radiol 38:160-166

86. Yang X, Ye X, Zheng A et al (2014) Percutaneous microwave ablation of stage I medically inoperable non-small cell lung cancer: clinical evaluation of 47 cases. J Surg Oncol 110:758-763

87. Healey TT, March BT, Baird G, Dupuy DE (2017) Microwave ablation for lung neoplasms: a retrospective analysis of long-term results. J Vasc Interv Radiol 28:206-211

88. Moore W, Talati R, Bhattacharji P, Bilfinger T (2015) Five-year survival after cryoablation of stage I non-small cell lung cancer in medically inoperable patients. J Vasc Interv Radiol 26:312-319

89. McDevitt JL, Mouli SK, Nemcek AA, Lewandowski RJ, Salem R, Sato KT (2016) Percutaneous cryoablation for the treatment of primary and metastatic lung tumors: identification of risk factors for recurrence and major complications. J Vasc Interv Radiol 27:1371-1379

90. Ni X, Han JQ, Ye X, Wei ZG (2015) Percutaneous CT-guided microwave ablation as maintenance after first-line treatment for patients with advanced NSCLC. Onco Targets Ther 8:3227-3235

91. Lin M, Liang SZ, Wang XH et al (2017) Clinical efficacy of percutaneous cryoablation combined with allogenic NK cell immunotherapy for advanced non-small cell lung cancer. Immunol Res 65:880-887

92. Lencioni R, Crocetti L, Cioni R et al (2008) Response to radiofrequency ablation of pulmonary tumours: a prospective, intention-to-treat, multicentre clinical trial (the RAPTURE study). Lancet Oncol 9:621-628

93. Hasegawa T, Takaki H, Kodama $\mathrm{H}$ et al (2020) Three-year survival rate after radiofrequency ablation for surgically resectable colorectal lung metastases: a prospective multicenter study. Radiology 294:686-695

94. VogI TJ, Naguib NN, Gruber-Rouh T, Koitka K, Lehnert T, Nour-Eldin NE (2011) Microwave ablation therapy: clinical utility in treatment of pulmonary metastases. Radiology 261:643-651

95. Vogl TJ, Eckert R, Naguib NN, Beeres M, Gruber-Rouh T, Nour-Eldin NA (2016) Thermal ablation of colorectal lung metastases: retrospective comparison among laser-induced thermotherapy, radiofrequency ablation, and microwave ablation. AJR Am J Roentgenol 207:1340-1349

96. de Baere T, Tselikas L, Woodrum D et al (2015) Evaluating cryoablation of metastatic lung tumors in patients-safety and efficacy: the ECLIPSE trialinterim analysis at 1 year. J Thorac Oncol 10:1468-1474

97. Callstrom MR, Woodrum DA, Nichols FC et al (2020) Multicenter study of metastatic lung tumors targeted by interventional cryoablation evaluation (SOLSTICE). J Thorac Oncol 15:1200-1209

\section{Publisher's Note}

Springer Nature remains neutral with regard to jurisdictional claims in published maps and institutional affiliations. 